\title{
ARTICLES
}

\section{HUMAN EXPERIMENTATION AND HUMAN RIGHTS*}

\author{
JAY KATZ**
}

\section{INTRODUCTION}

A dilemma confronts physician-investigators in the conduct of research with patient-subjects. As physicians they are dedicated to caring for their patients, healing their pain, reducing their suffering. As investigators they are dedicated to caring for their research, advancing knowledge for the benefit of science and future patients. These two commitments conflict whenever an individual physician-investigator comes face to face with an individual patientsubject. Indeed, in this encounter between two persons, four personae confront one another: the physician, the investigator, the patient in need of immediate

* A revised and extended version of a paper presented at St. Louis University School of Law on March 19, 1993, and as the Ipolitas Benedict Bronushas Lecture at the University of Maryland School of Medicine on April 2, 1993.

I want to express my thanks to George J. Annas, Robert A. Burt, Jesse A. Goldner, Robert J. Levine, Lainie F. Ross, Elizabeth van Dusen, Katherine Weinstein and Alan J. Weisbard for their helpful comments on earlier drafts of this article. My current research assistant, Steven D. Lavine, assisted me in preparing this article for publication and his thoughtful observations shaped its final version. I am particularly indebted to my former research assistant, Peter D. Mostow, with whom over the past two years I discussed everything contained in this article. His contributions influenced my thinking and I cannot thank him enough. Finally, I want to express my gratitude to my wife Marilyn A. Katz. From the first draft to its final version I discussed with her everything contained in this article, and her critical wisdom, though not specifically acknowledged, is reflected throughout.

** Elizabeth K. Dollard Professor Emeritus of Law, Medicine and Psychiatry, and Harvey L. Karp Professorial Lecturer in Law and Psychoanalysis, Yale Law School. 
help, and the subject who may himself be helped or who may help future patients.

This dilemma is new to the practice of medicine, which in the past only served patients' individual therapeutic needs. Only during the last fifty years, subsequent to World War II, did medical research increase in magnitude unprecedented in the millennia of medical history. ' Indeed, in today's world medical practice often encompasses both research and therapeutic aspects. The research component of any medical intervention, however, may not serve the individual therapeutic interests of patients. Instead, their well-being is subordinated to the dictates of a research protocol designed to advance knowledge for the sake of future patients.

In the aftermath of World War II the world was also confronted, as it had never been before, with the terrible human costs which human experimentation could entail. The revelation of the medical experiments conducted by Nazi physicians during the war, ${ }^{2}$ and, twenty-five years later the discovery of the Tuskegee Syphilis Study conducted by Public Health Service physicians in the United States $^{3}$ before, during, and after the Nazi concentration camp experiments had taken place, led to the realization that even medical progress can exact an intolerable price. Both revelations, and others as well, had a decisive impact on the promulgation of codes and regulations for the protection

1. See David J. Rothman, Strangers at the Bedside, 53-54 (1991).

Congress gave the [National Institutes of Health] (NIH) . . . the budgetary resources to expand on the work of the [Committee on Medical Research]. In 1945 the appropriation to NIH was approximately $\$ 700,000$. By 1955 the figure had climbed to $\$ 36$ million; by $1965, \$ 436$ million; and by $1970, \$ 1.5$ billion, a sum that allowed it to award some 11,000 grants, about one-third requiring experiments on humans. Id.

2. See Trials of War Criminals before the Nuremberg Military Tribunal, Volumes I \& II, The Medical Case, U.S. Government Printing Office (1948) [hereinafter TrIALS of War Criminals]; The Nazi Doctors and the Nuremberg Code, (George J. Annas \& Michael A. Grodine eds. 1992).

3. From 1932 until 1972, physicians of the U.S. Public Health Service conducted an experiment, the so-called Tuskegee Syphilis Study, in Macon County, Alabama, involving 399 black persons afflicted with syphilis. The subjects had not been informed that they were participating in an experiment to study the natural history of untreated syphilis. Instead, they thought that they were under the medical care of the U.S. Public Health Service. The study was terminated in 1972 at the recommendation of the Tuskegee Syphilis Study Ad Hoc Advisory Panel. For detailed accounts, see U.S. DePaRTMENT of HeALTH, EDUCATION, AND WELFARE, PUBlic HEAlth SERVICE, FINAL REPORT OF THE TUSKEGEe SyPHILIS STUDY AD HOC ADVISORY PANEL (1973) [hereinafter TUSKEGEE SYPHILIS STUDY]; JAMES H. JONES, BAD BLOOD (1981); and Alan Brandt who discovered evidence unavailable to the Panel which documented the deceptions practiced by the U.S. Public Health Service physicians throughout the course of the study. Alan M. Brandt, Racism and Research: The Tuskegee Syphilis Study, 8 HASTINGS CENTER REPORT 21-29 (Dec. 1978). 
of subjects of research. The requirements of consent ${ }^{4}$ and informed consent, ${ }^{5}$ based on principles of autonomy and self-determination, ${ }^{6}$ became central prescriptions for the protection of subjects of research.

What transpired at Auschwitz and Tuskegee would not have led to regulations of the human experimentation process had these events been viewed as isolated occurrences, ascribable to causes utterly distinct from ordinary contemporary research practices. The regulations were a response to an appreciation that important lessons could be learned from these events of relevance to contemporary research. They were also a response to the realization, questioned by some, ${ }^{7}$ that reliance on the ethical conscience, inculcated in physician-investigators during their medical education, provided insufficient protection to the human rights of subjects of medical research.

In this article I shall argue that these newly promulgated requirements and other safeguards-for example, Institutional Review Boards (IRBs) charged with the obligation to review and approve research proposals ${ }^{8}$ - still do not satisfactorily protect the rights of patient-subjects to inviolability of personhood and body. In exploring this problem my ultimate intent is to stimulate discussion on the need to provide greater protection to patientsubjects' rights to self-determination and bodily integrity whenever they are used as means for the ends of human progress. I shall argue that respect for individual autonomy and for self-determination, which informed consent is intended to safeguard, will remain hollow aspirations until the nature and quality of the conversations between physician-investigators and patientsubjects about participation in research are radically transformed. ${ }^{9}$ Inviting such participation for the sake of science, society, and future patients is an awesome request which, in a democratic society committed to respect for human rights, requires the most punctilious attention to disclosure and consent.

Before proceeding, I should make it clear that I do not intend to discuss research with vulnerable groups, such as children or the mentally impaired,

4. See infra notes 50-51 and accompanying text.

5. See infra notes $\mathbf{5 2 - 5 4}$ and accompanying text.

6. For a discussion of the principle of autonomy, see infra note 66 .

7. See Henry K. Beecher, Ethics and Clinical Research, 274 NEw ENG. J. MED. 1354 (1966).

The ethical approach to experimentation in man has several components, two are more important than the others, the first being informed consent. ... Secondly there is the more reliable safeguard provided by the presence of an intelligent, informed, conscientious compassionate responsible investigator.

Id. at 1360 (emphasis added).

8. See infra notes $92-93$ and accompanying text.

9. For a detailed discussion of the kind of conversations I envision in therapeutic settings, see Jay Katz, The SIlent World of DOCTOR and Patient (1984) [hereinafter The SILENT WORLD], particularly Chapter 6, Respecting Autonomy: The Obligation for Conversation, id. at 130-164. 
who do not have the capacity to give their consent. My focus is on the many patient-subjects who have the capacity to consent. Nor shall I say a great deal about investigators' ethical obligations to consider carefully whether the research project is important enough, and based on solid methodological grounds, to warrant asking human beings to join them in their endeavors. Clearly, consent is a necessary, but not sufficient, justification for using human beings as subjects for research; they deserve only to be used for experimental purposes when an important research question is in need of careful elucidation. Finally, I also shall not address the problem of physical harm which patientsubjects may suffer whenever they are parties to research. While some of the subjects are inevitably harmed, I grant the point frequently made, that as a group they may be harmed physically less, or at least not more, than are patients with similar diseases in therapeutic settings. ${ }^{10}$ I exclude consideration of physical harm, however, for another important reason. I want to distract attention from the prevalent and extensive debate on the permissible limits of physical harm to subjects ${ }^{11}$ and, instead, draw attention to the neglected and scant debate on the justifications for encroachments on subjects' rights to decisional authority in the conduct of research. ${ }^{12}$

10. P.V. Cardon et al., Injuries to Research Subjects, 295 NEW ENG. J. MED. 650-54 (1976). See also ROBERT J. LEVINE, ETHICS AND REgULATION OF CLINICAL RESEARCH 39-40 (2d ed. 1986) [hereinafter ETHICS AND REGULATION].

11. Wikler identified as the central moral problem in human experimentation "the possibility of subjects being injured or hurt." He went on to say that "[t]he other issues involved [such as informed consent] are far from negligible; but I believe that if [physical injury] were not a factor, human experimentation would not be the moral issue of the same order as it is now." Daniel Wikler, The Central Ethical Problem in Human Experimentation and Three Solutions, 26 CLIN. RES. 380 (1978). If Wikler is correct, then this article seeks to raise the consciousness of the medical community and the public about the great harm done by the disrespect accorded to the dignitary rights of subjects of research.

12. Two recently reported experiments which received considerable press attention are examples in point.

(1) Hepatitis B Study: During a drug trial conducted at the National Institutes of Health, five out of fifteen participants died some time after the administration of an experimental drug, Fialuridine (FIAU), that had shown promise in the treatment of Hepatitis B. Lawrence L. Altman, Fatal Drug Trial Raises Questions about 'Informed Consent', N.Y. TIMES, Oct. 5, 1993, at B7 [hereinafter Fatal Drug Trial]. The principal investigator correctly averred that "the public must understand that "drugs can do harm just as much as they do good," for despite the best intentions and care, injuries will accompany experimental investigations as they do therapeutic interventions. Id. at col. 4. Questions, however, were also raised about the adequacy of the informed consent process. For example, "Dr. [Judith] Swazey [co-director of a major study of review boards and consent forms for the National Institutes of Health] said that the term 'new medication' was misleading. [The principal investigator] should have used the term 'experimental anti-viral compound' on the form and underlined it." Id. at cols. 4-5. My reading of the Clinical Research Protocol and the Informed Consent Form suggests that it adequately disclosed the risks of the study. See Jay H. Hoofnagle, Six-Month Course of FIAU for Chronic Hepatitis B (Feb. 10, 1993) (on file with author) [hereinafter Research Protocol]. At the same time, and in agreement with 
More importantly, I shall argue throughout this article that the protection of the rights of research subjects to self-determination cannot be safeguarded until a number of underlying problems affecting the informed consent process in decisive ways have been resolved. The underlying problems are these: (1) The obfuscation of the distinction between therapy and research and the

Swazey but generalizing on her observation, the informed consent form did not make crystal clear that this was purely an experimental study. To be sure, if the promise of therapeutic benefit materializes the subjects will benefit, but for now they must appreciate that, similar to other experimental interventions, their participation could expose them to grave unknown risks. In this instance, such a forthright acknowledgement was particularly important since in the prior pilot study "[p]otential side effects of FIAU were seen in two patients but in both cases FIAU did not clearly appear to play a major role." Id. at 5. The death of one of the patients in the pilot project was ascribed to other causes and, from the vantage point of hindsight, was probably an incorrect assessment. The death of five participants, of course, deserved investigation and from my reading of the protocol would have established that the investigators took great care to avoid such a possibility. The question, however, remains whether the patient-subject knew that they had agreed to join the experimenters on a voyage into the unknown that could shatter their limbs or lives. That fact should also have been highlighted, as it was not, in the informed consent form. The unfortunate and perhaps unavoidable death of five subjects thus can easily divert attention from a crucial issue: the importance of paying the most punctilious attention to disclosure and consent.

(2) The IL-2 Study: In another experiment, prominent cancer researchers confessed to injecting a drug, IL-2, into "the brain tumors of dying patients to see if it would help them." Philip J. Hilts, Researchers Admit Study With Drugs Had No O.K., N.Y. TIMES, Oct. 28, 1993, at B5 col. 1. The drug had not been approved for such use by the FDA and the investigators had not submitted their protocol to the hospital's Institutional Review Board (IRB). The newspaper account does not mention whether the patient-subjects were informed about their participation in an experiment and the circumstances surrounding it. What particularly caught my attention in reading the story was that "the United States Attorney's office in Manhattan investigated the case [and decided] not to prosecute . . . at least in part because no apparent harm was done to the patients, who were near death from brain tumors." Id. Again the focus is on physical harm and not on the harm inflicted by disrespecting the decisional authority of the patients involved. If the investigators had discussed with their patients the investigational nature of the study and the patients, aware of their desperate condition, had agreed, then, beyond infractions of federal regulations, a major question that remains is when, if ever, can unapproved dnugs be used with subjects' consent? The same question has arisen in research with unapproved drugs for AIDS patients. In my view, both they and terminally ill patients can be apprised of the status of such drugs and such patients who are so aware of their desperate, well nigh hopeless, situation, may then be quite willing to opt for participation. As long as they are protected from physicianinvestigators' spurious promises and other deceptive exploitations of their necessitous circumstances, there may be nothing wrong with honoring their consent. Indeed, respect for autonomy may dictate it. Since it will give them a measure of hope-and what else is left to them at this most agonizing time in their lives-why deprive them of such solace? The danger of unscrupulous invitations, of course, remains but careful review of both the reasonableness of the scientific proposal and the forthrightness of the informed consent process can do much to ensure that the patient-subjects know to what they are consenting. 
accompanying confusion of patients and subjects; ${ }^{13}$ (2) the impact of the ideology of medical professionalism on the conduct of human experimentation; ${ }^{14}(3)$ the unclarity about the different tasks of medicine and research; ${ }^{15}$ and (4) the impact on the informed consent process on the mindset of physician-investigators and the principles that govern the invitation to participation in research. ${ }^{16}$ Finally, I shall suggest that the resolution of any inevitably persisting tensions between the inviolability of person and the acquisition of knowledge cannot be left to the discretion of physicianinvestigators or local IRBs. If any encroachments on citizen-patient-subjects' rights to self-determination prove to be necessary, it should require a thoroughly considered and explicit congressional mandate which now does not exist. It should also require the establishment of a national body with the authority to formulate rules for, as well as to administer and review, the human experimentation process. $^{17}$ A recent research project conducted with schizophrenic patients will illustrate these contentions. ${ }^{18}$

\section{THE RESEARCH-THERAPY DISTINCTION}

Physician-investigators have long maintained that clinical research and therapy, more often than not, are indistinguishable; that the drugs or therapies they subject to scientific study frequently are, or could be, proffered to patients in therapeutic settings; and that the only difference between their scientific endeavors and clinical practice resides in the objective evaluation of efficacy and risk-benefits to which they submit their interventions. Thus, since vast uncertainties and ignorance about effectiveness and risk-benefits are ubiquitous in the practice of medicine, every medical intervention, therapeutic or investigative in intent, constitutes an experiment. ${ }^{19}$ Moreover, investigators

13. See infra notes $19-34$ and accompanying text.

14. See infra notes $35-55$ and accompanying text.

15. See infra notes 56-63 and accompanying text.

16. See infra notes $64-90$ and accompanying text.

17. See infra notes 91-101 and accompanying text.

18. See infra notes 102-136.

19. For example, Thomas Chalmers stated: "It is extremely hard to distinguish between clinical research and the practice of good medicine. Because episodes of illness and individual people are so variable, every physician is carrying out a small research project when he diagnoses and treats a patient." Quoted in ETHICS AND REgULATION, supra note 10, at 3. While Levine is correct that in recent years new definitions of what constitutes research have been formulated, the obfuscation of subject and patient described in this section continue to obliterate the research/therapy distinction, at least in investigators' interactions with research subjects. Id. at 3-10. More generally, Royall documented the convictions of many investigators who continue to defend the ethics of clinical trials on the basis of the unsatisfactory state of clinical practice:

[I]f therapy A were known to be better than B, then there would be no need for a [clinical trial]. And if it is not known, then the physician who believes that $A$ is better has no sound basis for recommending $\mathrm{A}$; his belief represents only a personal opinion, an 
are apt to argue that in clinical practice patients are exposed to unnecessary, scientifically unproven, ineffective, and at times dangerous therapies about which patients learn little because their physicians believe in the therapies and their unwarranted beliefs are shared by many of their professional peers. In this view, clinical research differs from practice only in its endeavors not to perpetuate these uncertainties, but to resolve them once and for all for the benefit of future patients and perhaps even for the patient-subjects involved in clinical trials. Indeed, investigators maintain that clinical research is an enterprise more moral than clinical practice because ultimately it will safeguard patients and future patients from the slings and arrows of useless, if not dangerous, therapies. Therefore, it is grossly unfair not to extend the considerable discretion which doctors enjoy in making decisions on behalf of patients in therapeutic settings to investigators, and instead subject them to onerous review procedures regarding informed consent.

These contentions speak to the latitude physicians are given generally in making decisions on behalf of patients, despite the requirement for informed consent. For even in clinical practice the doctrine of informed consent continues to be an empty ritual not only because it does not require physicians to disclose the uncertainties inherent in their interventions, about which investigators are so correctly concerned, but also because the doctrine remains so inattentive to its underlying idea that patients and physicians must make decisions jointly, with ultimate decision-making authority residing in the patient and not in the physician. ${ }^{20}$ Yet, all these problems notwithstanding, the doctrine of informed consent, as currently articulated, imposes similar disclosure and consent obligations for therapy and research, ${ }^{21}$ with the only

unscientific hunch, and is not a proper basis for responsible professional judgment.

Richard M. Royall, Ethics and Statistics in Randomized Clinical Trials, 6 STAT. SCI. 51, 55

(1991). He then quotes Freund who shares these views:

[M] uch of what the surgeon assumes he knows is not based on solid scientific data, but rather on training, experience, and reinforcement. The choice of treatment is neither more nor less likely to be correct if made arbitrarily than if assigned randomly in the clinical trial. The two courses of action can thus be considered ethically equivalent in terms of patient risk.

...

[E]ven an opinion held with strong conviction is not a sufficient basis for ethical action; passionate opinion does not make an incorrect opinion into a correct one. Id.

20. For a more detailed discussion, see Jay Katz, Duty and Caring in the Age of Informed Consent and Medical Science: Unlocking Peabody's Secret, 8 HUMANE MED. 187, 188-89 (1992) [hereinafter Duty and Caring].

21. The most significant difference between the common law doctrine of informed consent for therapy and the federal requirements for informed consent in research, resides in the "therapeutic privilege exception." It permits physicians to withhold information if it would "foreclose a rational decision, or complicate or hinder the treatment, or perhaps even pose psychological damage to the patient." Canterbury v. Spence, 464 F.2d 772, 789 (D.C. Cir. 1972). 
difference being that for research the informed consent process is subjected to review by IRBs. In application, however, disclosure and consent are taken all too lightly in both settings because physicians and physician-investigators do not consider patients and patient-subjects as equal partners in the decisionmaking process.

All the arguments about similarities between research and practice or complaints about inequitable burdens overlook an issue that speaks to the crucial importance of informed consent in research: In therapeutic encounters, unlike research encounters, physicians are expected to attend solely to the welfare of the individual patient before them. Throughout medical history this expectation has given physicians considerable discretion and authority to make decisions on behalf of patients. More recently, to be sure, such discretion and authority have been questioned on many grounds. I shall mention only two. First, since many of the diagnostic and therapeutic options now available allow patients to make choices that can have a decisive impact on the quality of future life, what a physician thinks is best may not necessarily comport with a patient's overall needs. ${ }^{22}$ Second, because the available options may have

Courts in the past have construed the privilege not to disclose most liberally, but the Canterbury court cautioned that it must be "carefully circumscribed ... for otherwise it might devour the disclosure rule itself. The privilege does not accept the paternalistic notion that the physician may remain silent simply because divulgence might prompt the patient to forego therapy the physician feels the patient really needs." Id. at 789. In a recent case, the Court of Appeals of California reduced the scope of the therapeutic privilege even further by requiring that in instances of hopeless prognosis (the most common situation in which the privilege has been invoked) the patient be provided with such information: "If not the physician's duty to disclose a terminal illness, then whose?" Arato v. Avedon, 11 Cal. Rptr. 2d 169, 181 n.19 (1992). The California Supreme Court reversed. Arato v. Avedon, 858 P.2d 598 (1993). Its opinion made too much of an issue raised by the plaintiffs which led the appellate court to hold that doctors must disclose "numerical life expectancy. information." Id. at 604. To be sure, disclosure of statistical information is a complex issue, but in focusing on it, the supreme court's attention was diverted from a more important new disclosure obligation promulgated by the appellate court: the duty to inform patients of their dire prognosis. The supreme court did not comment on that obligation and, instead, reinforced the considerable leeway granted physicians to invoke the therapeutic privilege exception to full disclosure: "[W]e decline to intrude further, either on the subtleties of the physician-patient relationship or in the resolution of claims that the physician's duty to disclose was breached by requiring the disclosure of information that may or may not be indicated in a given treatment context." Id. at 607.

22. See ThE SILENT WORLD, supra note 9, at 8.

The objectives of health and cure that supposedly unite physician and patient in a common pursuit can rarely be fully realized. Furthermore, these objectives can be pursued in a variety of ways, each with its own risks and benefits. The physician's personal and professional ethics and experience may dictate one course: the patient's needs, wishes and priorities, motivations, and expectations may indicate another one. Thus, health turns out to be an ambiguous state about which doctors and patients may have conflicting expectations ....

Id. 
an impact on physicians' economic rewards, physicians' self-interests can readily influence their professional recommendations. ${ }^{23}$

Indeed, the doctrine of informed consent was promulgated in 1957 in response to both of these new realities. ${ }^{24}$ Judges thought that the introduction of new powerful diagnostic and treatment modalities, which promised great benefits but could also inflict considerable harm, required that patients be given a greater voice in the medical decision-making process. ${ }^{25}$ Yet, informed consent notwithstanding, the physician-patient encounter continues to be shaped by the belief, shared by doctors and patients, that in therapeutic settings doctors at least try to do their level best for the individual patient who seeks their help and, therefore, the doctor's recommendations can be trusted.

In clinical research, on the other hand, patient-subjects are also being used for the ends of science. One cannot dismiss with impunity the implications of this difference. ${ }^{26}$ In these situations investigators are committed both to real, present patients and abstract, future patients. Individual patient-centered therapy gives way to a collective patient-centered endeavor in which the

23. See, e.g., Arnold S. Relman, Dealing with Conflict of Interest, 313 NEw ENG. J. MED. 749 (1985); Bruce J. Hillman et al., Frequency and Costs of Diagnostic Imaging in Office Practice-A Comparison of Self-Referring and Radiologist-Referring Physicians, 323 NEW ENG. J. MED. 1604 (1990); Jean M. Mitchell \& Elton Scott, New Evidence of the Prevalence and Scope of Physician Joint Ventures, 268 J.A.M.A. 80 (1992).

24. Salgo v. Leland Stanford Jr. University Board of Trustees, 317 P.2d 170 (1957). At the end of his opinion, Justice Bray introduced the doctrine of informed consent in a short, albeit confusing, paragraph. For a detailed analysis, see THE SILENT WORLD, supra note 9, at 60-65.

25. The situation in Salgo, see supra note 24 , involved the use of a new diagnostic procedure to locate a block in the abdominal aorta. It required injection of a dye, sodium urokon. In 1954, aortography had not been performed in sufficient numbers in the San Francisco Bay area to constitute routine procedure. The doctors admitted that they had not disclosed to Martin Salgo the risk of the procedure which resulted in a permanent paralysis of his lower extremities. In Natanson v. Kline, 350 P.2d 1093 (1960), Irma Natanson suffered severe injuries from cobalt radiation, administered subsequent to a mastectomy for breast cancer. In 1955, cobalt radiation, instead of conventional $x$-ray treatment, had barely been introduced in Wichita, Kansas. Dr. Kline admitted that he had not informed his patient of the hazards of cobalt radiation or the availability of other post-operative treatment modalities. My reading of the two opinions suggests that the justices were astounded and troubled by the undisputed facts in both cases; that, without any disclosure, new technologies were employed which not only promised great benefits but also could expose patients to formidable and uncontrollable risks. Natanson, unlike Salgo, discussed the informed consent doctrine in some detail and it marked the true beginning of a new common law doctrine.

26. Consider the views of Foster Lindley:

I did not realize that decisions ... regarding altemative therapies, have themselves become matters of life and death. That people die in the service of abstract, controversial, statistical proofs, I cannot accept. That they die at the hands of physicians who mistakenly prefer one therapy to another, I can accept. Some will see an inconsistency there; I do not.

Royall, supra note 19 , at 74 . 
abstraction of the research question tends to objectify the person-patient. ${ }^{27}$ It does so to a significantly greater extent than in therapeutic interactions, even though similar problems of objectification arise in therapeutic settings when doctors attend too much to the disease of the body in the bed and not to the person before them. ${ }^{28}$

The readiness with which clinical research continues to be viewed as an extension of clinical practice, both similarly grounded in the millennia-long Hippocratic commitment to the welfare of the individual patient, overlooks the transformation of medical practice since the age of medical science. ${ }^{29}$ Throughout most of medical history, research was limited to careful bedside observation of the effects of innovative treatments, with the interests of the individual patient as a polestar. In today's world, on the other hand, the interests of patient-subjects may yield to varying extents to the interests of science. This revolutionary development has not been accompanied by a thoroughgoing re-examination of physicians' ethical obligations in a postHippocratic age.

Examples in point are the many cooperative clinical trials, generally randomized clinical trials (RCTs), ${ }^{30}$ in which institutions throughout the

27. See infra note 66 and accompanying text.

28. In a conversation between a senior physician and a medical intern, the former asked how much the intern knew about "patients as human beings." The question led to a rather nonproductive exchange which the intern ended abruptly with the exasperated comment: "I cannot answer your questions. You're interested in patients. I'm interested in the disease in the body in the bed." RAYMOND S. DUFF \& AUgust B. HOLlINGSHEAD, SICKNESS AND SOCIETY 128 (1968).

29. Medical practice has become transformed in other ways as well which should have led to greater involvement of patients in the medical decision-making process:

Medicine's recent ascent from empiricism to science has brought forth spectacular technologic advances in the diagnosis and treatment of disease. Today the numerous options available for the treatment of many diseases allow patients greater choice. Moreover, the introduction into medicine of scientific reasoning, aided by the results of carefully conducted research, permits doctors to be more discriminating between knowledge, ignorance and conjecture in their recommendations for or against a treatment.

For the first time in medical history, it is possible, even medically and morally imperative, to give patients a voice in medical decision making; possible, because knowledge and ignorance can be better specified; medically imperative, because a variety of treatments are available, each of which can bestow benefits or inflict harm; morally imperative, because patients, depending on the lifestyle they wish [to lead] after treatment, must be given a choice.

Duty and Caring, supra note 20, at 189.

30. The randomized clinical trial (RCT) is generally regarded as the gold standard for the evaluation of therapeutic agents.

The RCT has four main elements. 1) It is "controlled," i.e., one part of the subject population receives a therapy that is being tested while another part, as similar as possible ...., receives either another therapy or no therapy. . . 2) The significance of its results is established through statistical analysis... 3) When it is feasible, a double-blind 
United States participate and which are designed to evaluate the effectiveness of various treatment modalities for breast cancer, coronary artery disease, prostate cancer and stroke. In the conduct of such clinical trials, conflicts between the interests of patients and science are ever-present and are all too readily swept aside by viewing patient-subjects less as subjects and more as patients who can only benefit from participation in such clinical trials. Convictions of therapeutic benefit thus shape decisively the informed consent dialogue in clinical research, aided and abetted by patients' belief that their doctors have their interest uppermost in mind. ${ }^{31}$

This belief is at best only partially warranted. Investigators have other personal and professional interests which can only be kept in check if both physician-investigators and patient-subjects fully appreciate that both are engaged in an enterprise in which patient-subjects are also being asked to serve as means for science's ends and that other therapeutic alternatives are often available which do not involve a research dimension.

From all I have said so far, it follows that a major problem which compromises the protection afforded to subjects of research resides in the obfuscation of the boundaries between clinical research and clinical practice. It is therefore imperative to view clinical research as a distinct category, sharply delineated from clinical practice. ${ }^{32}$

The need for such sharp distinctions may fade once physicians no longer exercise such sweeping authority over patients' medical fate. In The Silent World of Doctor and Patient, I not only questioned this authority but also argued that the doctrine of informed consent has insufficiently reduced this authority. ${ }^{33}$ Thus, patients have not been provided with meaningful opportunities to make their own choices. ${ }^{34}$ If the time ever comes when patients'

technique is employed. That is, neither the investigator nor the subject knows until the conclusion of the study who is in the treatment or control group. . . . 4) It is randomized, i.e., the therapies being compared are allocated among the subjects by chance.

ETHICS AND REGULATION, supra note 10, at 185. RCTs are frequently employed. "In 1975 there were over 750 separate protocols involving over 600,000 patient-subjects. These numbers are for NIH [National Institutes of Health] sponsored trials only; many additional RCTs are conducted or sponsored by drug companies or with funding from other sources." Id. at 186. For a complete account of the design and conduct of RCTs, see id. at 187-212.

31. Recently George J. Annas aptly noted: "Researchers tend to think that they do good, that they don't do bad. And patients feel the same way; they tend to minimize or totally downplay the risks." Fatal Drug Trial, supra note 12, at col. 2-3.

32. See supra note 21 and accompanying text.

33. See THE SILENT WorLd, supra note 9, at 85-103.

34. Alan Meisel said:

Instead of informed consent, what we usually find in the practice of medicine is what my colleague Loren Roth has called "informed compliance." Doctors make decisions about the treatment patients should have, and then they provide whatever information is necessary to get the patient to go along with the recommendation. Patients are not given information to facilitate their decision-making process. That patients "make" decisions 
rights to autonomy and self-determination are truly respected, the problem to which I now turn - the impact of the ideology of medical professionalism on clinical research-will be less pressing. It is this ideology which has given, and continues to give, physicians considerable latitude to decide for patients, in the belief that doctors can be trusted because their self-interest will yield to patients' interests. While I have already suggested that this is a questionable assumption for therapeutic settings, it surely is an untenable one for clinical research where physician-investigators have dual allegiances- to their patientsubjects and the research protocol.

\section{The Ideology of Medical Professionalism}

The presumption of physician authority over the medical needs of their patients has been the bedrock of the ideology of professionalism. Throughout history, physicians have maintained that patients' needs are best served by following doctors' orders. As stated by the influential sociologist Talcott Parsons: "[The physician's] competence and specific judgments and measure cannot be competently judged by the layman. The latter must . . . take these judgments and measures on 'authority.' . . . The doctor-patient relationship has to be one involving an element of authority-we often speak of 'doctor's orders." 35 Physicians' insistence on complete authority over the needs of patients has been compellingly supported by another claim: that patients are incapable of understanding medicine's esoteric knowledge. As stated by Howard Becker:

Professions ... are occupations which possess a monopoly of some esoteric and difficult body of knowledge. [This knowledge] consists not of technical skills and the fruits of practical experience but, rather, of abstract principles arrived at by scientific research and logical analysis. This knowledge cannot be applied routinely but must be applied wisely and judiciously to each case. $^{36}$

Most physician-investigators were first socialized as physicians and indoctrinated in the ideology of professionalism. While, in theory, it has yielded ground to the doctrine of informed consent, in practice, the impact of that ideology has, at best, only diminished. It is, therefore, not surprising that investigators continue to point to the esoteric knowledge problem. In addition, investigators maintain that this problem is compounded in clinical research

is a myth, at least as much (if not more) because they are not given an adequate opportunity to do so as because they are inherently unable to do so.

Alan Meisel, Comments to T.M. Grundner, More on Making Consent Forms More Readable, 4 IRB 9 (Jan. 1982).

35. TAlcott Parsons, THE Social SySTEM 464, 465 (1954).

36. Howard Becker, The Nature of a Profession, in EXPERIMENTATION WITH HUMAN BEINGS 186-189 (1993). 
because patient-subjects are even less capable of understanding the additional medical and scientific complexities which a clinical trial seeks to resolve. Thus, they argue that patient-subjects' consent, given on the basis of such disclosures, would be even more spurious than it is for therapy. Moreover, since they view subjects of research as patients, they also argue that full disclosure would do violence to the principle of beneficence, ${ }^{37}$ which stresses the caring obligations of doctors toward their patients. Disclosure, they say, would reveal that customary treatments to which patients would be exposed if they were to decline to become subjects are beset by much uncertainty as to which treatment is best, effective, or harmful. All this can only make patients unduly frightened, cause them to lose hope in what medicine has to offer, and strip them of trust in their physicians.

For all these reasons, the argument goes, any respect for patient autonomy must be balanced against the principle of beneficence, of caring for the suffering patient who happens to be also a subject of research. In countless conversations with physician-investigators, I have heard paternalism and beneficence, and not respect for autonomy, defended as guiding principles for the conduct of research.

Thus, under the ideology of professionalism the autonomy of physicians is maintained at the expense of patients' autonomy. I have long believed that this ancient ideology no longer serves patients' interests well in an age of medical science and informed consent. Surely it cannot be transported into the research setting, where it is joined by the ideology of medical science, with its commitment to objectivity and search for ultimate answers that will benefit mankind. Such an unwarranted alliance has fateful consequences to persons who are not merely patients but also subjects.

37. For an extensive discussion of the principle of beneficence, see TOM L. BEAUCHAMP \& JAMES F. ChildRess, PRINCIPLES OF BIOMEDICAL ETHICS 148-182 (2d ed. 1983).

Morality requires not only that we treat persons autonomously and that we refrain from harming them, but also that we contribute to their welfare, including their health . . . . In its most general form, the principle of beneficence asserts the duty to help others further their important and legitimate interests. The duty to confer benefits and actively to prevent and remove harms is important in biomedical and behavioral contexts, but equally important is the duty to balance possible goods against the possible harms of an action.

Id. at 148-49.

Note that "the duty to balance" may require giving greater weight to beneficence than autonomy. While this may be necessary with incompetent patients and research subjects, such balancing is often carried on in interactions with competent patients and research subjects. This then leads to withholding crucial information from patients in order not "to distress" them. While even in therapeutic encounters with competent persons such "balancing" is questionable, it is inappropriate to balance possible goods against harms in the conduct of clinical research. 
The legal doctrine of informed consent has had little impact on moderating physician authority. ${ }^{38}$ This is not surprising since the doctrine's underlying assumption, that patient autonomy deserves respect, has been foreign to physicians' thinking throughout medical history. ${ }^{39}$ Though it is true that patients now receive more information about the risks and benefits of the recommended intervention than they did in earlier times, this change also obscures how little has changed. For such disclosures notwithstanding, the decision-making process continues to be under physician control.

Thus, the consequences of importing the ideology of medical professionalism into research settings are far-reaching. It permits, as I have already noted, viewing subjects as if they were patients. It permits physician-investigators to extend the invitation to participate in research with the same authority to which they have become accustomed as a result of their prior socialization as physicians. It permits not fully informing patient-subjects about uncertainties and risks inherent in clinical research on grounds of beneficence which physicians traditionally invoke for clinical practice. Any of these reasons, however questionable in therapeutic settings, are unwarranted justifications for non-disclosure in the context of research.

\section{RESPECT FOR AUTONOMY AND BODILY INVIOLABILITY}

Twenty years ago, in the Introduction to my book Experimentation with Human Beings, I wrote:

When human beings become the subjects of experimentation . . . tensions arise between two values basic to Western society: freedom of scientific inquiry and protection of individual inviolability.... At the heart of this [value] conflict

38. See the perceptive comments by Alan J. Weisbard on informed consent:

[I]n its attempt to translate the moral ideal of informed consent into a set of workable legal rules adapted to the technical requirements of the litigation process, the law has transformed that ideal into little more than a legal "duty to warn" of risks of medical treatment. This duty is measured not by the actual informational needs of the individual patient, but by the hypothetical needs of "reasonable patients" or by the prevailing norms of disclosure of the medical community. While purporting to assure respect for individual self-determination, the inaptly named law of informed consent has done little to "inform" the unique and sometimes idiosyncratic needs, concerns, and fears of individual patients on whose "consent" so much is said to rest. Indeed, one can plausibly maintain that the legal doctrine has done more to teach physicians how to practice medicine "defensively" (so as to minimize legal liability) than it has to foster physician-patient relationships that permit and encourage patients to participate actively and knowledgeably in decisions concerning their care.

Alan J. Weisbard, Informed Consent: The Law's Uneasy Compromise with Ethical Theory, 65 NEB. L. REV. 749, 751 (1986).

39. See THE SILENT WORLD, supra note 9, at 1-29. "The idea that patients may also be entitled to liberty, to sharing the burdens of decision with their doctors, was not [at least until recently] part of the ethos of medicine." Id. at 2. 
lies an age-old question: When may a society, actively or by acquiescence, expose some of its members to harm in order to seek benefits for them, for others, or for society as a whole? ? $^{40}$

My question assumed, at least implicitly, both the necessity of conducting human research and the inevitability of harm; it asked only when may society "expose some of its members to harm." I did not ask then as I shall do now: When, if ever, can it be justified to use human beings as means for the ends of others?

In now raising the question of justification, I do not wish to deny the morality of human experimentation. Ultimately it is necessary to conduct human trials in order to acquire the necessary knowledge to alleviate human suffering. I wish only to call attention to the fact that investigators' oftinvoked moral right to engage in human experimentation has left insufficiently considered the morality of how the invitation to participation in research must be extended so that the rights of subjects to be secure in their person and body remain sacrosanct.

Sir Isaiah Berlin addressed this fundamental issue in a different context when he asked: "In the name of what can [we] ever be justified in forcing men to do what they have not willed or consented to?"41 His eloquent answer was this:

[T] o manipulate [men], to propel them towards goals which [we] see, but they may not, is to deny their human essence, to treat them as objects without wills of their own, and therefore to degrade them. This is why to lie to men, or to deceive them, that is, to use them as means for [our], not their own, independently conceived ends, even if it is to their own benefit, is, in effect, to treat them as subhuman, to behave as if their ends are less ultimate and sacred than [our] own. ... For if the essence of men is that they are autonomous beings-authors of values, of ends in themselves ... - -then nothing is worse than to treat them as if they were not autonomous but natural objects . . . whose choices can be manipulated . . . ${ }^{42}$

Sir Isaiah speaks here to the importance of safeguarding the principle of autonomy. But in addition to this liberty interest, another human interest must be considered: the right to bodily integrity. John Locke encompassed both rights when he wrote that "every Man has Property in his own Person. This no Body has any Right to but himself." 43

The United Nations' International Covenant on Civil and Political Rights in Article 7 juxtaposes the rights to autonomy and bodily integrity: "No one

40. JAY KATZ, EXPERIMENTATION WTTH HUMAN BEINGS 1 (1972) [hereinafter EXPERIMENTATION WITH HUMAN BEINGS].

41. Isaiah Berlin, Two Concepts of Liberty, in FOUR ESSAYS ON LIBERTY 136-37 (1969).

42. $I d$.

43. John LOCKE, Two Treatises on Government 305 (Peter Laslett ed., 1960). 
shall be subjected to torture or to cruel, inhuman, or degrading treatment or punishment. In particular, no one shall be subjected without his free consent to medical or scientific experimentation." 44 For years, I was puzzled by the inclusion of experimentation and torture within the same Article rather than giving each separate status as the Covenant does for the other rights it seeks to safeguard. I now see the connection. The drafters of the Covenant probably wished to convey that human experimentation "without his [or her] free consent" constitutes inhuman and degrading treatment akin to "torture," no matter what the motives of the investigator. ${ }^{45}$ In the Western world we place a high value not only on autonomy but also on the inviolability of bodily integrity. Both make any unconsented invasions of subjects' bodies repugnant even if the physical risks are minimal.

Some commentators have suggested that too much is made of respect for autonomy in human research. While I do not share their views, I now want to add respect for bodily integrity, which is highly valued in our American jurisprudence, ${ }^{46}$ as another reason for safeguarding citizens' rights to feel secure in their bodies. Since physicians have been given considerable discretion to inspect, touch and invade patients' bodies, it is easy to overlook that this privilege cannot be extended to research without a prior relentless

44. United Nations International Covenant on Civil and Political Rights, art. 7 (1966), in THE HuMAN Rights READER (Walter Laqueur \& Barry Rubin eds., 1979).

45. It could be argued that the juxtaposition of "scientific experimentation" and "torture" was solely a response to the sadistic ways in which the concentration camp research was carried out and, therefore, a prohibition only of such egregious conduct. If true, then I wish to broaden the implications of Article 7.

46. The United States Supreme Court first articulated the right to bodily integrity over a century ago, explicitly noting that such a right is fundamental to the common law: "No right is held more sacred, or is more carefully guarded, by the common law, than the right of every individual to the possession and control of his own person, free from all restraint or interference of others, unless by clear and unquestionable authority of law." Union Pacific Ry. v. Botsford, 141 U.S. 250 (1891) (refusing to order a plaintiff in a tort action to submit to a surgical examination). Since then, the Court has found a Fourth Amendment right to bodily integrity in the "right of the people to be secure in their persons ... against unreasonable searches and seizures." Winston v. Lee, 470 U.S. 753, 759 (1985) (refusing to order a criminal suspect to undergo surgery to remove a bullet). Although this right is not absolute, the Court has stressed the importance of bodily integrity in strongly worded opinions: "Illegally breaking into the privacy of the petitioner, the struggle to open his mouth and remove what was there, the forcible extraction of his stomach contents ... [, these] are methods too close to the rack and the screw to permit of constitutional differentiation." Rochin v. People of California, 342 U.S. 165, 171 (1952). More recently Justice Stevens in Planned Parenthood v. Casey, 112 S. Ct. 2791, 2840 (1991), citing Rochin, declared: “One aspect of [a woman's constitutional interest in liberty] is a right to bodily integrity, a right to control one's person." See also FRANCIS HILLIARD, 1 THE LAW OF TORTS 197 (2d ed. 1861) ("The plainest and simplest legal rights are those of the person. A man owns his body and limbs more unquestionably and unqualifiedly than his stock in trade or his farm. [One's body] belong[s] absolutely to the individual, and to him alone."). Id. 
scrutiny about whether any State interest can be so compelling to override constitutional safeguards to both autonomy and bodily integrity.

Sir Isaiah's haunting question, raised in a different context, requires answers: Can manipulation of subjects of research, propelling them towards goals which we see but they may not, be justified in the name of medicine, science, and/or the State? I would answer: Not easily and, if at all, only under carefully circumscribed circumstances. The reasons for my answer are intertwined. First, it is difficult to defend the proposition that we can use human beings as means for others' ends, without their unequivocal consent unless authorized by a clear societal mandate, subsequent to a searching public debate; and second, medical research is by-and-large conducted with patients and by physicians under the aegis of medicine and physicians' primary Hippocratic commitment to the welfare of the individual. This commitment becomes tainted when, without a patient-subject's full knowledge, we allow the interests of science and society to intrude on the physician-patient relationship.

The historian Mario Biagioli in his essay on the Nazi concentration camp experiments pleaded that we need "to understand how [medical] science became (and could again become) implicated in [such a] tragedy." ${ }^{.47}$ It did become implicated because the contributions which science in its own right makes to the objectification of human beings, i.e., the transformation of persons into objects and data, was reinforced by the political ideology of the Nazi State, which totally objectified Jews and Gypsies by considering them "lives not worth living." 48 This unholy alliance led to the atrocities and sadism perpetuated against the subjects of research for the sake of medical science never before or since seen in the Western World. Yet, it would be a mistake to view the concentration camp experiments merely as a singular aberration rather than as an event which has much to teach us about research practices in the contemporary world. In Nazi Germany the State decreed that some "lives [are] not worth living," 49 and medical scientists then seized the opportunity to pursue research in atrocious ways. While it is true that only with the active collaboration of the State can science produce an Auschwitz and Dachau, it is equally true that in contemporary research the claims of science invite a less perceptible, but nonetheless troublesome, disrespect for the person. Unless the greatest care is taken, medical science and physicianinvestigators are always trapped into making tragic choices for the sake of science and at the expense of the human beings who serve as subjects of

47. Mario Biagioli, Science, Modernity, and the 'Final Solution,' in PROBING THE LIMITS OF REPRESENTATION (Saul Friedlander ed., 1992).

48. See infra note 77 and accompanying text.

49. The idea that "lives not worth living" deserve to be eliminated gained wide currency in medicine during the 19th century. The debate focused on the merits of destroying the insane to relieve society of a terrible burden. For a detailed account, see ROBERT N. PROCTOR, RACIAL HYGIENE: MEDICINE UNDER THE NAZIS 177-222 (1988). 
research. This is the eternal lesson to be learned from Auschwitz.

Respect for the person is the only counterweight to such tragedies. The judges at Nuremberg who passed judgment on the Nazi physicians recognized this and in uncompromising language spoke to the inviolability of research subjects. The Tribunal's first principle for the conduct of research-“"the voluntary consent of the human subject [of research] is absolutely essential"SO - eschewed any consideration of competing claims. This principle, soon after its promulgation, was attacked as being too visionary and too inhospitable to the advancement of science. ${ }^{51}$ New codes and regulations for the conduct of research were then enacted which attempted to balance the claims of science and the inviolability of research subjects. ${ }^{52}$ Balancing, however, necessitates discretion, and discretion invites physician-investigators to make tragic choices about future versus present lives.

The U.S. federal regulations on informed consent in research, ${ }^{53}$ while protecting the rights of subjects better than had been the case in the past, do not go far enough in emphasizing the centrality of the inviolability of the human rights of research subjects, if not as an ethical obligation than surely as a societal obligation in a democracy. The drafters of the federal regulations needed to consider that their promulgations would confer on physicians a societal mandate to engage in clinical research and to use individuals for the good of society, a mandate not envisioned by the Hippocratic commandment to "use treatment to help the sick according to my ability and judgment." 54 A mandate to conduct research, on the other hand, is different in intent and implication and, therefore, the regulations on informed consent should have been formulated in a way that place considerable restrictions on the use of patient-subjects. To safeguard their autonomy would have required paying the most careful attention not only to the criteria for informed consent but also to the process of obtaining informed consent.

The drafters of the federal regulations should have explicitly insisted that taking informed consent seriously in research negotiations obligates physician-

50. Trials of War CRIMINals, supra note 2, at 181.

51. The critics were, of course, correct in pointing to the Nuremberg Code's lack of provisions for conducting research with children, the mentally disabled, and perhaps even with prisoners. Special provisions must be drafted for such vulnerable populations, and the extent of their participation in research should be precisely specified. The Code was limited, as are largely my comments throughout this article, to research with persons who have the capacity to consent.

52. See Human Experimentation, Code of Ethics of the World Medical Association, Declaration of Helsinki, 2 BRIT. MED. J. 177 (1964). For a discussion of this Declaration, see Jay Katz, The Consent Principle of the Nuremberg Code: Its Significance Then and Now, in THE NAZI DOCTORS AND THE NUREMBERG CODE, supra note 2, at 227-39. There I argued that in the Declaration of Helsinki, in contrast to the Nuremberg Code, "concerns over the advancement of science began to overshadow concerns over the integrity of person." Id. at 234.

53. 45 C.F.R. $\$ 46$ (1983) (providing for protection of human subjects).

54. HIPPOCRATES, I HIPPOCRATES 299-301 (W.H.S. Jones trans., Harvard Univ. Press 1972). 
investigators to spend considerable time with prospective patient-subjects. They should have provided explicit instructions on the length to which investigators must go in explaining themselves and their intentions so that patient-subjects will not be misled. Respect for the subjects' human rights dictates that they know that the decision to participate in research entails making a gift for the sake of others.

The drafters of the federal regulations insufficiently cautioned physicianinvestigators against viewing clinical research as an extension of clinical practice. In not construing it more emphatically as a novel and distinctly separate activity, they contributed to importing the ideology of medical professionalism into the conduct of research.

Before promulgating the federal regulations, great pains should have been taken to alert Congress and the public that any societal mandate to conduct clinical research had to be sharply distinguished from the earlier societal mandate to superintend the health needs of citizen-patients, which was delegated to physicians at the turn of the 20th century. ${ }^{55}$ That mandate cannot easily be transferred to medical research settings. At a minimum, it required a prior careful scrutiny and public debate about the limits to be imposed on the prerogatives of investigators to use human beings for scientists' and society's sake. Such a debate needed to be carried on with the same intensity as the one that has repeatedly taken place on the question as to whether it is preferable to rely on a military draft or a volunteer army to protect citizens' and society's interests.

\section{The Task of Clinical Research}

The tasks of clinical practice and clinical research are different. Robert Levine has persuasively argued that the objectives of investigators and practitioners are not the same:

The goal of research-the development of generalized knowledge-is advanced by working according to a detailed [relatively inflexible] protocol. . . . [Thus] an appropriate question might be: "What is the antihypertensive effect of administration of this thiazide diuretic in a specified dose range for six weeks to patients with moderately severe hypertension?" In medical practice a more appropriate question is: "What is the best way to control the [blood pressure] of this patient who not only has moderately severe hypertension but also has diabetes, congestive heart failure, and recently lost her job?"s6

From this, Levine, on another occasion, drew a crucial conclusion:

[T] he individualized dosage adjustments and changes in therapeutic modalities are less likely to occur in the context of a clinical trial than they are in the

55. See THE SILENT WORLD, supra note 9, at 39-42.

56. Robert J. Levine, Informed Consent in Research and Practice: Similarities and Differences, 143 AMA ARCHIVES OF INTERNAL MEDICINE 1229, 1231 (1982). 
practice of medicine. This deprivation of the experimentation ordinarily done to enhance the well-being of a patient is one of the burdens imposed on the patient-subject in a clinical trial. ${ }^{37}$

In another article, Levine perceptively described an imaginary dialogue between a patient-subject and a physician-investigator about participation in a randomized, placebo controlled study on the effectiveness of a new antihypertensive agent:

Do you mean to say you are asking me to spend six months taking either an inert substance or one that you have no cause to suspect is either better or worse than that inert substance when the risk of taking a placebo entails approximately a 28 percent chance per year of having a severe complication such as stroke, malignant hypertension, heart failure, or death? You offer me an invitation to participate in such an RCT when I could instead take any of the many antihypertensive drugs which are already approved by the FDA and which would reduce my risk of a major complication to 1.6 percent per year? Why would any rational person do that? ? $^{58}$

Levine concluded "Why, indeed!"59 It is difficult to believe that many patients will consent to participation in such a study if adequately informed about risks and alternatives. Levine's dialogue also highlights the formidable task which physician-investigators would face if they were to explain forthrightly to their patient-subjects what is currently known about the effectiveness of antihypertensive drugs; or if they were to alert patient-subjects in a placebo-controlled study that the purpose of the active agent is to mitigate aspects of the disease process that can lead to lethal or disabling complication and that the placebo will not protect them from such consequences; or if they were to alert patient-subjects that preliminary evidence in studies of the effectiveness of two different therapeutic agents has already accumulated on the superiority of one of the agents over the other in the treatment of disease.

Research is not entirely a voyage into the utterly unknown. When a clinical trial is contemplated, considerable information, though not yet scientifically validated, is generally available to suggest that experimental treatments may promise to be beneficial. Thus, in situations in which the experimental treatment is compared with existing standard therapy, all kinds of known or conjectured evidence has accumulated about their respective merits. Patient-subjects generally remain ignorant of most, if not all, of these complexities of knowledge and ignorance. ${ }^{60}$ Instead, patient-subjects are told

57. Ethics AND Regulation of Clinical ResearCh, supra note 10, at 10.

58. Robert J. Levine, Uncertainty in Clinical Research, 16 L. MED. \& HEALTH CARE 174, 178 (1988).

59. Id.

60. Levine states:

Quite commonly at the time a randomized clinical trial is begun, the investigators have available quite a bit of evidence about the agents to be tested. In the United States, for 
that it is not yet known which treatment is best, but as Schafer observed, "this statement is misleading at best, deceptive at worst."61 Very few patients are aware that by the phrase "scientifically validated knowledge" the physicianinvestigator only means "confirmed by a controlled trial."62 Such statements conceal information from patient-subjects about alternative treatments whose effectiveness does not rise to a ninety-five percent level of confidence or that are based on clinical experiences or on more poorly designed earlier trials. All this suggests that informed consent does not just involve presenting scientific information to patient-subjects, but requires physician-investigators to translate that information into language relevant to subjects' life experiences and interests.

Investigators with whom I have talked confirm Schafer's observation. They admit that they know many things about risks and benefits, but they also insist that this information need not be communicated because they really do not know and will only know the true scientific state of affairs at the end of a rigorously conducted scientific study. Thus, to tell patients precious little is ethically justified. Moreover, even those who in principle are committed to obtaining their patient-subjects' consent will also admit that, in practice, their invitation to participation is affected by the belief that they have already carefully considered the project-its risks and benefits-and concluded that no undue physical harm will come to the subjects and, therefore, they can take some license with the informed consent process. In such conversations an old conviction ultimately surfaces; that subjects are better protected by the investigator being the "guarantor of [their] rights and safety" 63 than by their own consent which rarely is a "valid" one. Thus, in reality, the idea that the investigator is best situated to protect subjects of research continues to have a significant impact on the minds of investigators and the ways they extend their invitations.

\section{The Nature of the INFormed Consent Process in Clinical RESEARCH}

If the tensions between the inviolability of research subjects and the advancement of knowledge are to be resolved in favor of respect for the

example, the results of extensive experience with new drugs obtained during clinical investigations or in medical practice in other countries are often available.

Robert J. Levine, The Use of Placebos in Randomized Clinical Trials, 7 IRB 112 (Mar.-Apr. 1985). Similar information is also available in clinical research studies other than randomized clinical trials.

61. Arthur Schafer, The Randomized Clinical Trial: For Whose Benefit?, 7 IRB 4, 5 (Mar.Apr. 1985).

62. Id.

63. G. Long et al., Measurement of Anti-Arrhythmic Potency of Drugs in Man: Effects of Dehydrobenzperidal, 28 ANESTHESIOLOGY 318-19 (1967). 
human rights of the subjects, the mindset which investigators bring to the invitation of participation, the ethical principles which govern the invitation, and the conversations which physician-investigators and patient-subjects must engage in require re-examination. I shall take up each in turn.

\section{A. The Mindset of Physician-Investigators}

Physician-investigators, before approaching a potential patient-subject, must first rid themselves of the customary attitudes which in the past shaped, if not determined, their invitation to patient-subjects. ${ }^{64}$ A morally valid consent in research settings requires a radically new personal and professional commitment to the patient-subjects and the informed consent process: Physicianinvestigators must see themselves as scientists only and not as doctors. In conflating clinical trials and therapy, as well as patients and subjects, as if both were one and the same, physician-investigators unwittingly become double agents with conflicting loyalties. Only if they first know who they truly are can they begin to make the subject understand the burdens he or she is assuming when an invitation to participate in clinical trials is extended.

64. In The Silent World I drew attention to the "irrational and unconscious expectations [which] influence physicians' conduct." I noted that "[e]arly in his explorations, Freud recognized that doctors' unconscious has an impact on their relations with patients, and [that] he gave these manifestations the name 'countertransference." THE SILENT WORLD, supra note 9, at 147. I then argued that

[a] broader definition of countertransference that encompasses not only physicians' personal conduct but also their deeply ingrained professional attitudes toward patients will move to center stage a re-examination of the impact on physician-patient interactions of a great many unquestioned professional attitudes. These attitudes include the need to appear authoritative, the importance of hiding uncertainties from patients, the need to view patients as incompetent to participate in decision making, and the belief that patients' welfare depends on patients' trusting doctors' capacities to know what is in patients' best interests.

... My broader view of countertransference suggests that not only physicians' personal beliefs but also their professional beliefs are influenced by irrational and unconscious factors. Indeed, the most pernicious countertransference problem may turn out to be that in their professional interactions with patients, physicians view themselves as too rational and their patients as too irrational. A more realistic view of the balance between rationality and irrationality in both parties will itself improve decision making between physicians and patients. The projection of irrationalities originating within physicians onto patients is indeed one of the most pervasive and fateful countertransference reactions.

Id. at $149,150$.

I should mention, as I made clear in my book, that by "irrational" I only meant "not subjected to careful conscious reflection." Thus, in the context of this article I wanted to flag the unexamined countertransference reactions of investigators that are grounded in their commitment to advance knowledge but without sufficient reflection of the impact of these motives on the human rights of subjects of research. 
Moreover, since loyalty to the research protocol will take precedence over faithfulness to the therapeutic mission, and since physician-investigators will tend to view the person before them as a patient and not as a subject, the tragic fact that human beings are used for the ends of others can readily become obliterated. It is then not surprising that physician-investigators, without fully knowing it, become confused about the nature of their task, as well as about their perceptions of themselves and their patient-subjects.

The investigators who appear before patient-subjects as physicians in white coats create confusion. Patients come to hospitals with the trusting expectation that their doctors will care for them. ${ }^{65}$ They will view an invitation to participate in research as a professional recommendation that is intended to serve their individual treatment interests. It is that belief, that trust, which physician-investigators must vigorously challenge so that patient-subjects appreciate that in research, unlike therapy, the research question comes first. This takes time and is difficult to convey. It can be conveyed to patientsubjects only if physician-investigators are willing to challenge the misperceptions that many patients bring to the invitation.

\section{B. The Primacy of Autonomy}

Physician-investigators must extend the invitation to participation in research with a thoroughgoing commitment to the principle of autonomy. ${ }^{66}$

65. See infra note 77 and accompanying text.

66. In their authoritative book Principles of Biomedical Ethics, Beauchamp and Childress define the concept of autonomy thusly: "Autonomy is a form of personal liberty of action where the individual determines his or her own course of action in accordance with a plan chosen by himself or herself. . . A A person's autonomy is his or her independence, self-reliance, and selfcontained ability to decide." TOM L. Beauchamp \& James F. ChIIDRESS, PRINCIPLES OF BIOMEDICAL ETHICs 56 (1st ed. 1979). Beauchamp and Childress continue:

It is one thing to be autonomous and to apprehend that others are acting autonomously, but quite another to be respected as an autonomous agent and to respect the autonomy of others. To respect autonomous agents is to recognize with due appreciation their own considered value judgments and outlooks even when it is believed that their judgments are mistaken. To respect them in this way is to acknowledge their right to their own views and the permissibility of their actions based on such beliefs. And to grant them this right is to say that they are entitled to such autonomous determination without limitations on their liberty being imposed by others.

Id. at 58. For purposes of this article I accept their formulation of autonomy. In The Silent World I offered a view of autonomy which is also based on psychoanalytic considerations but which does not disagree with their views on the respect to be accorded to autonomous choices:

Respect for psychological autonomy requires that both parties pay caring attention to their capacities and incapacities for self-determination by supporting and enhancing their real, though precarious, endowment for reflective thought. In conversation with one another, patients may uncover mistaken notions [and] physicians may uncover [some of] their unconscious preferences and biases. $\therefore$. Without conversation, individual self-determination can become compromised by condemning physicians and patients to the isolation of 
Edmund Pellegrino, in a recent article on the "Ethical Dilemmas in Clinical Research," explored the moral dilemmas faced by clinical investigators. He located them in the inevitable conflict among three values: "for science, it is truth; for medicine, it is beneficence toward the patient; and for the investigator as an individual, it is self-interest." ${ }^{" 67}$ He concluded that

[t] he safe rule in [clinical research] is to favor beneficence over scientific rigor when the two seem to be in conflict or when in doubt. The possible loss of knowledge cannot outweigh the possibility of harm to the subject even if the utilitarian calculus indicates great benefit to many and harm to only a few. ${ }^{68}$

He granted the scientist, however, "a certain latitude or 'discretionary space' in the pursuit of knowledge" which is difficult to define by rules and which "must be narrowly defined. Respect for persons and the imperative of beneficence take precedence over scientific curiosity." 69 Yet earlier he seemed to extend the discretionary space when he expressed the hope "that the investigator will judiciously balance the patient's interests and those of the scientific protocol."

Pellegrino can be understood or misunderstood as giving considerable latitude to investigators, and for two reasons. First, he often moves from research with competent subjects to research with incompetent subjects without explicitly stating that entirely different considerations apply to both groups. ${ }^{71}$

solitary decision making, which can only contribute to abandoning patients prematurely to an ill-considered fate.

THE SILENT WORLD, supra note 9, at 128. Moreover:

Even though choices are influenced by psychological considerations, it is one thing to appreciate that fact and quite another to interfere with choice on the basis of speculations, or even evidence, about underlying psychological reasons. ... Short of substantial evidence of incompetence, choices deserve to be honored.

Id. at 112-13.

67. Edmund D. Pellegrino, Beneficence, Scientific Autonomy, and Self-Interest: Ethical Dilemmas in Clinical Research, GEO. MED. 21 (1991).

68. Id. at 27.

69. Id. at 26-27.

70. Id. at 22 .

71. Similarly, the celebrated Belmont Report on principles and guidelines for human research is confusing by not making clear distinctions between the principles that should govern research with competent and incompetent persons. It considered three basic principles to be "particularly relevant to the ethics of research .... : respect for persons, beneficence and justice." THE NATIONAL COMmission fOR THE PROTECTION OF HUMAN SUbJECTS OF BIOMEDiCAL AND BEHAVIORAL RESEARCH, U.S. DEPARTMENT OF HEALTH AND HuMAN RESOURCES PUB. No. (OS) 78-0012, The BELMONT REPORT: ETHICAL PRINCIPLES AND GUIDELINES FOR THE PROTECTION of HuMAN SUBJECTS OF RESEARCH 4 (1978). The report continues:

1. Respect for Persons ... incorporates at least two ethical convictions: first that individuals should be treated as autonomous agents, and second, that persons with diminished autonomy are entitled to protection ....

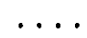


Then one can readily overlook that he means to invoke the principle of beneficence only for research with incompetent subjects. He suggests that with competent subjects a "morally valid consent" is essential. Yet, later on he seems to modify his position when he writes: "It is the investigator who decides how much to tell the patient or family, what facts to emphasize, which to withhold, and how to present them." from issues germane to therapy to those that pertain to research without clearly distinguishing between the two settings. Thus, Pellegrino may be correct in saying that one of the value conflicts "for medicine . . . is beneficence toward the patient," ${ }^{73}$ but for clinical research with competent patients, respect for autonomy must be the guiding principle.

At times, Pellegrino seems to agree. He writes that

[t]he intellectual autonomy of the scientist is autonomy held in trust, . . [i.e.] the conscious acknowledgement by the investigator that he or she is allowed freedom to pursue rigorous scientific goals in human experimentation only if the welfare of the patient is always respected as primary and superior to the

To respect autonomy is to give weight to autonomous persons' considered opinions and choices while refraining from obstructing their actions unless they are clearly detrimental to others.

....

In most cases of research involving human subjects, respect for persons demands that subjects enter into research voluntarily and with adequate information.

....

2. Beneficence. Persons are treated in an ethical manner not only by respecting their decisions and protecting them from harm, but also by making efforts to secure their wellbeing.

$$
\text { ... }
$$

The obligations of beneficence affects both individual investigators and society at large, because they extend both to particular research projects and to the entire enterprise of research.

Id. at 4-7.

The examples given for justifying invocation of the principle of beneficence, however, address only vulnerable populations, e.g., children, prisoners, and the mentally ill. Yet, in setting forth three principles for the general conduct of research and then appealing to such vague terms of art as protection from "harm" and securing "well-being," for invoking the beneficence principle, can readily create the impression that with competent subjects too, autonomy may at unspecified times have to yield to beneficence. Respect for persons deserved a more unequivocal, or at least more precise, formulation.

For an interesting discussion of serious difficulties in the Belmont Report, see Ernest Marshall, Does the Moral Philosophy of the Belmont Report Rest on a Mistake?, 8 IRB 5-6 (Nov.-Dec. 1986). He notes, for example, that "the point of Kantian principles is precisely to say that certain things cannot be 'balanced out,' i.e., if certain actions are unjust or disrespectful of persons then they are wrong and therefore simply should not be done." Id. at 6 .

72. Pellegrino, supra note 67, at 24.

73. Id. at 21 . 
values of science and self-interest. ${ }^{74}$

Pellegrino's use of the word "welfare" could suggest that it encompasses not only prevention of physical injury but also respect for subjects' autonomous choice. Welfare, however, is often used only to refer to preventing physical injury; therefore, it would have been better if he had emphasized that in clinical research with competent subjects it only pertains to respect for autonomy.

I raise these issues also because Pellegrino places so much faith in "the personal morality of the clinical investigator" whom he considers "the ultimate safeguard of the safety of the experimental human subject."75 But his hybrid concept "autonomy held in trust," an amalgam of autonomy and benevolence, alienates the rights of subjects to be authors of their own fate. The implied idea that investigators are permitted to exercise a trusteeship over persons' autonomy is particularly problematic in today's world where respect for subjects' self-determination is not as abiding a motivating consideration in the conduct of research as is the advancement of science for the sake of mankind. ${ }^{76}$

Respect for autonomy imposes numerous burdens on the physicianinvestigator. First, he must not allow disclosures to be shaped by paternalistic or beneficent concerns that patient-subjects will make decisions which are not in their "best interests." Second, he or she must not allow disclosures to be shaped by concerns that patient-subjects will learn that the customary treatments which they may continue to take, should they decline the more promising experimental treatments, offer no hope for the alleviation of their suffering. Nor should disclosures be shaped by concerns that patient-subjects' trust in medicine will be undermined once they learn about the uncertainties inherent in all medical treatments, nor by concerns over upsetting hospitalized patients if they were to appreciate that they, too, are being asked to yield their individual interests to the interests of scientific investigations.

Moreover, physician-investigators must reflect on the fateful impact of their commitment to the ideology of medical science-its ethos to acquire knowledge for the sake of mankind-on the invitation to participation in research. Medical scientists share with their colleagues from the natural sciences a commitment to the pursuit of truth, objectivity, and the advancement

74. Id. at 26.

75. Id. at 21 .

76. The personal morality of the investigator would not be impugned if he or she were to give greater weight to the advancement of science than to autonomy. Indeed, Pellegrino noted that an investigator "faces a difficult task of balancing and ordering the values of truth and beneficence against each other." $I d$. at 25 . Thus, the question remains whether "autonomy-intrust" permits such balancing with both competent and incompetent subjects. Since his recent paper is a major contribution to the ethics of research, I discussed it at some length. I can only hope that I interpreted him correctly. 
of knowledge. The commitment to objectivity invites investigators' thought processes to become objectified and, in turn, to transform the human beings who are the subjects of research into data points to be plotted on a chart that will prove or disprove a research hypothesis.

Margaret Radin's observations about objectification illuminate this problem. In an article on women and people of color she noted that

[o]bjectification comes about through subordination when one culture conceives of certain characteristics of persons ... as marks of lesser personhood. These marks license manipulation of those who bear the marks, and also license refusal to recognize in them rights and other indices of respect otherwise conceived of as universally applicable to persons. ${ }^{77}$

This license was usurped or conferred on physicians in clinical practice, and since the age of medical science has been extended to clinical research. Objectification begins with patients and becomes intensified when subordination is also affected by attitudes toward gender, color, religion, social and economic status and, of course, by the scientific imperative of clinical research.

Furthermore, human beings should not be used lightly and cheaply to serve as means for the ends of others, even though they are so readily available in large numbers. Prior to extending an invitation to subjects, physicianinvestigators must give thought to the minimal number of subjects required for obtaining satisfactory answers to a research question and must conduct a literature search of existing studies which will make a repetition of an experiment unnecessary. Science's commitment to truth and progress, particularly when human beings are needed for purposes of research, ought to disdain inquiries where the truth is already apparent and progress already a reality.

Finally, as I have already suggested, physician-investigators must go to considerable length in extending the invitation to participate in clinical research so that they can rest assured that patient-subjects understand the implications of their consent. Pellegrino, in his discussion of "valid consent," sensitively describes the difficulty patients experience in "[separating] the physicianscientist role from the physician-healer."

77. Margaret J. Radin, Reflections on Objectification, 65 S. CAL. L. REV. 341, 346 (1991). Pellegrino is similarly concerned when he writes that "the values and standards [of science necessitate] a certain degree of objectivization of the subject under study. But in clinical investigations, the 'object' of study remains a human being." Thus, he cautions that "the canons of science may conflict with another set of values-those that define the endeavor of medicine." Pellegrino, supra note 67, at 22.

The objectification of patients is also illustrated by investigators' concerns in the outcome of a new treatment in terms of longevity while patients may be more concerned about the quality of life offered by one or the other treatment. For a detailed and sensitive discussion, see CHARLES Fried, Medical Experimentation: Personal INTEgrity and Social Policy (1974).

78. Pellegrino, supra note 67 , at 25. 
physician can easily obtain consent to an experimental protocol simply by emphasizing the hope of cure and downplaying the risk and the experimental nature of the treatment." ${ }^{\text {"9 }} \mathrm{He}$ cautions physicians that "[a] legally adequate consent form may not be morally valid [for a] morally valid consent aims at true 'con-sent,' an agreeing together." 80

Only respect for persons' autonomy and self-determination can guarantee "true 'con-sent,' an agreeing together"; otherwise, the invitation subtly becomes a request or even a demand. Invocation of the principle of beneficence, in the service of shielding patient-subjects from painful disclosures, can only mislead physician-investigators into "downplaying the risk and the experimental nature of the treatment." Whenever beneficence suggests withholding of information, the better solution would be to exclude patient-subjects from participation in clinical research.

\section{The Conversation}

To obtain a "morally valid consent [which] aims at true consent," is an inordinately difficult task. The physician-investigators must disclose to their subjects at least the following information: (1) that the subjects are not only patients and, to the extent to which they are patients, that their therapeutic interests, even if not incidental, will be subordinated to scientific interests; (2) that it is problematic and indeterminate whether their welfare will be better served by placing their medical fate in the hands of a physician rather than an investigator; (3) that in opting for the care of a physician they may be better or worse off and for such and such reasons; (4) that clinical research will allow doctors to penetrate the mysteries of medicine's uncertainties about which treatments are best, dangerous, or ineffective; (5) that clinical research may possibly be in the patient's immediate best interest, perhaps promise benefits in the future, or provide no benefit, particularly if the patient is assigned to a control (placebo) arm of a study; (6) that research is governed by a research protocol and a research question and, therefore, his or her interests and needs will yield to the claims of science; and (7) that physician-investigators will respect whatever decision the subject ultimately makes.

Conversing with patient-subjects in such a manner which will give them a clearer appreciation of the difference between clinical research and therapy is a daunting assignment. I have on occasions been asked, "How will investigators know when to stop the conversation?" My response has been that they will know when to stop once they have learned to begin the conversation with a commitment to respect for personhood; for only then will they not shirk their responsibility to be utterly forthright in disclosing the research dimension of their work and the alternatives available to their patient-

79. Id.

80. Id. at 24 . 
subjects. It is the spirit in which the conversation begins which is the problem. If that problem is better resolved, the end will take care of itself.

Levine once wrote that in the current climate of extending the invitation to participation in research, "[the informed consent] requirement [serves] as a pledge made by researchers that in the pursuit of their salutary mission they will not exploit people; [or that i]ndividual persons will not be involved as research subjects without their awareness or approval." 81 If he meant by "pledge" a symbolic gesture "to secure and maintain public confidence in scientific research," 82 rather than a true commitment, I would agree.

Guido Calabresi years ago expressed his doubts about informed consent serving as a "control system" for the value conflicts inherent in the conduct of research. He did not believe that it could in practice serve such a purpose. His argument was that "[c]onsent or its semblance keeps us from blatantly [destroying] the fabric of our commitment to human dignity." convinced that informed consent need only serve such a limited symbolic function once the idea of shared decision making becomes a guiding commitment. Levine's and Calabresi's observations, however, identify the mutual deceptions in which scientists and the public engage in order not to unduly impede scientific research. The public, propelled by its longings to benefit from the advancement of science, has made common cause with scientists' demand for freedom of inquiry by acquiescing to the human costs which research entails. The symbolic bow to informed consent then allows the public and scientists to have it both ways. Forcing a public debate on the morality of human experimentation may put an end to the all too silent evasion of confronting any tragic choices that must be made. To be sure, "public confidence in scientific research" is justified on the ground that physicianinvestigators will take great care in not exposing patient-subjects to unnecessary physical harm. But this is a different matter.

The disclosure obligations I have set forth so far emphasize the need to pay particular attention to explaining to patient-subjects how participation in research differs from how they would ordinarily be treated or would expect to be treated. Thus, the first task in extending the invitation is to be absolutely clear about the research dimension of the invitation, its implications and possible consequences. Such disclosures do not require patient-subjects to understand the esoteric knowledge of medicine and science. Indeed, at present, subjects are overwhelmed with unnecessary scientific information that clarifies little and serves more the purpose of obscuring the crucial information that

81. Robert J. Levine, Deferred Consent, 12 Controlled CliniCal Trials 546 (1991) (emphasis added).

82. Id.

83. Guido Calabresi, Reflections on Medical Experimentation in Humans, 98 DAEDALUS 387 , 404 (1969). 
they need to know, ${ }^{84}$ such as the risks, benefits, alternatives, and uncertainties which patient-subjects face by their participation in clinical research, and the impact of participation, known and conjectured, on the quality of their future lives. Investigators have an obligation to translate scientific information into language which is relevant to patient-subjects' life and interests. Informed consent forms are so incomprehensible because they are written at a higher reading level than is appropriate for the intended population. ${ }^{85}$ In addition, they include too much distracting technical information of little consequence to the decisions which patient-subjects must make. Put another way, current informed consent forms often provide IRBs rather than the subjects with a better understanding of investigators' intentions.

Physician-scientists will be reluctant to converse with patient-subjects in the spirit of the recommendation that I have outlined. ${ }^{86}$ Such conversations take time, may have to extend over hours, perhaps even days, and must be continued until one is reasonably certain that the patient-subjects understand.

84. Alan Meisel has argued that the problem of the unreadability of informed consent forms is better resolved not "by improving [their] readability [but by abolishing them, even prohibiting] them by legal fiat if necessary." He then goes on to say that

[t]he problem is not the unreadability of consent forms; that is merely symptomatic. The real problem is that physicians, for the most part, do not consider informed consent to be an important part of the practice of medicine. ... Consent forms play no role in the informed consent process. Where used, they are intended merely to memorialize that in fact the informed consent process transpired.

Meisel, supra note 34.

Abolishing informed consent forms will not improve matters. As Meisel observed, physicians do not consider informed consent important and such attitudes will infect the oral informed consent process as well. Informed consent forms can be improved if their function were to truly inform patient-subjects about matters crucial to their decision. Too often they do not serve this purpose. See infra notes 117-124 and accompanying text.

85. Considerable literature exists on the "readability" of informed consent forms. For a recent article, see James R. Ogloff \& Randy K. Otto, Are Research Participants Truly Informed? Readability of Informed Consent Forms Used in Research, 4 ETHICS AND BEHAVIOR 239-252 (1991).

86. Royall discusses some of the obstacles to informed consent:

A more prosaic reason why informed consent is not a panacea is that in many cases it simply won't work. Sometimes too few patients will agree to participate in the study. And sometimes the consent process is simply too uncomfortable and time-consuming. Many physicians are reluctant to share their uncertainties with patients, and many patients do not want to hear about such uncertainties. Also, many patients know so little about research that to make them truly understand what they are being asked to do and why, to make their consent truly "informed," would require more time and effort than can reasonably be invested.

Royall, supra note 19 , at 58 . Since we have not had sufficient experience with an informed consent process as advocated in my article, we do not know whether it will work or not. Surely the process will require time and effort, but such a price must be paid if consent is to be taken seriously. 
Of course, subjects may still make decisions which they later on will regret because they then believe, perhaps correctly so, that they had not given their participation the thought it deserved. This is inevitable, and physicianinvestigators must not allow that possibility to tailor their disclosures in order to avoid burdening subjects with guilt feelings over having made the wrong decision (another variant of beneficence) or that they will agree to what investigators believe to be in subjects' better interests. Autonomous persons must be held responsible for their own mistakes and must not be protected from making them by subterfuge. As Justice Stevens once put it when he spoke about a pregnant woman's distress in deciding whether or not to undergo an abortion. "[I]t is far better to permit some persons to make incorrect decisions than to deny all individuals the right to make decisions that have a profound effect upon their destiny." 87

Thus, recruitment of subjects will prove to be more time consuming. Completion of research may also be delayed and, if too many patients refuse, selection bias will make some research impossible to conduct. Not only may scientific progress be impeded but physician-investigators' self-interests in recognition and advancement of their careers may be jeopardized. ${ }^{88}$ Scientific discoveries do not occur in isolation and, more often than not, scientists in many centers are pursuing similar inquires. The imperative to publish first is of crucial personal significance, because so much depends on it in terms of recognition, fame, future grants and prospects. A commitment to disclosure and consent entails paying a great personal price which can be moderated, however, if the collectivity of physician-investigators embrace these responsibilities or find new ways of conducting research which will make forthright disclosures less of a burden. ${ }^{89}$ It is also a great professional price to pay

87. Thomburgh v. American College of Obstetricians and Gynecologists, 106 S. Ct. 2169, 2189-90 (1986).

88. Pellegrino has given an excellent account of the impact on research practices of investigators' self-interests, be they advancement of careers, economic rewards, etc., or of their institutions' arrangements with pharmaceutical companies and other industries. Pellegrino, supra note 67 , at 24-25. "[T] hey pose a potential danger to experimental subjects. They can compromise beneficence, the central value in medicine." Id. at 25 .

89. Marcia Angell states:

I find it difficult to justify strategies to increase the accrual of patients if the result is that people do not act as they would if full and necessarily neutral information had been provided. It might be better in this situation to consider alternatives to randomized clinical trials. Several workers have emphasized that it is often scientifically adequate to use non-randomized controls in trials of treatments .... A final alternative, which deserves more attention, is better and more systematic analysis of available information; this might in some instances obviate the necessity for new studies.

Marcia Angell, Patients' Preferences in Randomized Clinical Trials, 310 NEW ENG. J. MED. 1385, 1386 (1984).

Science desires randomized clinical trials, it does not demand them. . . . [T] of randomized trials is exaggerated by the false dichotomy that is implied when historical 
because physician-investigators come to research out of a deeply felt dissatisfaction with the current state of medical knowledge and out of a painful awareness of the suffering of their patients.

Insufficient attention has also been paid to the current reality which places physician-investigators at the mercy of the institutions in which they work and the private and public grant agencies which support their research. Medical research since World War II has become a research-industrial complex. Academic institutions rely on the revenues which accrue from the assessment of indirect costs to the providers of grants. Research proposals have to be generated and completed at a rapid rate to assure future grant support. Thus, investigators are under considerable pressure to recruit subjects as quickly as possible to support the institutions' buildings, laboratories, staff and salaries. With respect to career advancement and future grant support, physicianinvestigators are thus the victims of an institutional system (their own institutions and the National Institutes of Health) which penalizes them if in fulfillment of their ethical disclosure obligations toward patient-subjects, the pace of research would be slowed. Both at the national and local levels this problem deserves careful consideration and sustained discussion. ${ }^{90}$

\section{A National Human InVESTIGATION BOARD}

The moral ambiguities inherent in the contemporary regulations of human research are also an inevitable consequence of policy makers' unwillingness to confront openly the lengths to which a democratic society like ours should go in protecting citizen-subjects' rights to autonomy and bodily integrity for

control trials are the only alternative discussed. In fact many of the weaknesses of historical controls can be avoided by using concurrent non-randomized controls. And of course comparing a treatment with both historical and concurrent controls can provide even stronger evidence about its efficacy.

Royall, supra note 19 , at 60 .

90. Pellegrino has commented on some of these problems:

Institutional pride or hubris is . . . a corrosive influence. The institution's drive to be "first" is a mixed motive; it can be effective in raising institutional morale and productivity, but it is also capable of submerging moral imperatives on grounds of exigency and "survival." In competition with other hospitals and universities, institutional pride can desensitize an institutional review board to certain dubious projects.

Pellegrino, supra, note 67, at 24.

The matter is further complicated when the health care industry enters long-term contractual arrangements with a university to support research. The usual proviso is that a company will support research facilities and personnel in return for privileged access and a share in the patenting rights to the products developed. These industry-university compacts are especially attractive today when governmental and philanthropic sources of research funding are insufficient. Some of our most prestigious universities have entered into what may well turn out to be Faustian compacts.

Id. at 25. 
the sake of medical science. I have already suggested that whatever societal mandate exists for the conduct of human research has not been subjected to intensive congressional and public scrutiny as to the morality and legality of the enterprise. Instead, as Edmond Cahn once put it, we have been all too willing, in our longing to conquer disease and death, "to possess the end and yet not be responsible for the means, to grasp the fruit while disavowing the tree, to escape being told the cost, until someone else has paid it irrevocably."91

The policy questions underlying the tensions between the inviolability of subjects of research and advancing the frontiers of knowledge require more careful articulation and resolution than can be gleaned from the federal regulations so far enacted. ${ }^{92}$ The concerns I have raised and the recommendations I have made need to be examined, debated and decided by a national regulatory body to which the IRBs can also turn for advice and guidance on difficult problems that require resolution.

The need for such a regulatory body, which I had already explored in Experimentation With Human Beings, ${ }^{93}$ was supported by my colleagues who served with me on the Tuskegee Syphilis Study Ad Hoc Advisory Panel. We had been appointed by the Assistant Secretary for Health of the Department of Health, Education and Welfare "to investigate the circumstances surrounding the Tuskegee, Alabama, study of untreated syphilis in the male Negro initiated by the United States Public Health Service in 1932." ${ }^{\text {"94 }}$ Our primary assignments were to make recommendations as to whether the Study should be terminated, to pass judgment on the ethics of the Study from its inception, and to make recommendations about necessary changes in "existing policies to protect the rights of patients participating in health research." 95

Among the many recommendations we made with respect to the third assignment, one urged that Congress establish a permanent body, which we called the National Human Investigation Board (NHIB), with the authority to regulate at least all federally supported research involving human subjects. We suggested that

[t]he primary responsibility of the National Human Investigation Board should be to formulate research policies, in much greater detail and with much more clarity than is presently the case. The Board [should also] promulgate detailed procedures to govern the implementation of its policies by institutional review committees. It [should] also promulgate procedures for the review of research decisions and their consequences. In particular, this Board should establish

91. Edmond Cahn, Drug Experiments and the Public Conscience, in DRUGS IN OUR SOCIETY 255, 260 (Paul Talalay ed. 1988).

92. See supra note 53 and accompanying text.

93. EXPERIMENTATION WITH HUMAN BEINGS, supra note 40, at 856-954.

94. TUSKEGEE SYPHILIS STUDY, supra note 3, at 2.

95. Id. at 1 . 
procedures for the publication of important institutional committee and Board decisions. Publication of such decisions would permit their intensive study both inside and outside the medical profession and would be a first step toward the case-by-case development of policies governing human experimentation. We [saw] such a development, analogous to the experience of the common law, as the best hope for ultimately providing workable standards for the regulation of the human experimentation process. ${ }^{96}$

Senator Edward Kennedy incorporated that proposal in a bill submitted to the Senate. ${ }^{97}$ His bill was never enacted and I believe that a major reason was the Senate's reluctance to expose to public view the value conflicts inherent in the conduct of research. Had the Senate seriously debated the bill, it would have been forced to consider whether inadequately informed subjects should ever serve as means for society's and science's ends. Instead, by inaction, it left such painful decisions to the low visibility handiwork of local IRBs.

I believed then, as I do now, that the rejection of a National Human Investigation Board was a mistake for many reasons. ${ }^{98}$ Most importantly, it precludes greater public visibility of the decisions made in the conduct of human experimentation. Current practices do not provide for either institutional review committees' publication of, or free access to, such decisions. This low level of visibility not only hampers efforts to evaluate and learn from attempts to resolve the complex problems of human research but also prevents the public at large from reacting to what is being done for the sake of the advancement of science.

Local IRBs cannot assume these and other functions that a National Human Investigation Board could serve, for yet another reason. As George Annas has observed, "IRBs as currently constituted do not protect research subjects but rather protect the institution and the institution's investigator."99

There is considerable truth to his allegation. The majority of IRB members are on the faculty of the institutions to which the investigators

96. Id. at 24.

97. S. 2072, 93d Cong., 1st Sess. (1973).

98. Such a Board, for example, should promulgate detailed regulations for research with vulnerable subjects. Moreover, it would have to address Ackerman's concerns that any absolute commitment to autonomy "suffers from fatal difficulties in an important range of situations. It is widely agreed that individuals have duties of beneficence to prevent substantial harm to other specific persons when doing so will involve no more than modest costs to their own interests." Terrence F. Ackerman, Balancing Moral Principles in Federal Regulations on Human Research, 14 IRB 4 (Jan.-Feb. 1992). If these concerns have merit, then the Board could consider Caplan's suggestion that a "general obligation [be imposed on persons] to participate in research." Arthur L. Caplan, Is there a Duty to Serve as a Subject in Biomedical Research?, 6 IRB at 1-5 (Sept.Oct. 1984).

99. George J. AnNaS, Judging Medicine 331 (1988). 
belong. ${ }^{100}$ They not only share similar interests and objectives but they also know, when sitting in judgment of a research protocol, that their proposals may soon be subjected to similar scrutiny. Thus, particularly in the murky area of informed consent, it is unlikely that members of IRBs will hold investigators to a standard of disclosure and consent that would protect the subjects of research if doing so would place impediments on the conduct of research and, in turn, affect the well being of their colleagues in decisive ways. $^{101}$

\section{A CASE EXAMPLE}

A research study conducted at the Neuropsychiatric Institute of the University of California, Los Angles, (UCLA) which began in the early 1980s and is still in progress, illustrates the problems I have discussed. To orient the reader, I briefly summarize three facts about the design of the experiment and two facts about its aftermath that are of concern to me: (1) The study required schizophrenic patients who had recovered from their psychotic disorders to be withdrawn from medication even though "[i]t is generally accepted that maintenance antipsychotic medication will benefit a substantial proportion of chronic schizophrenics."102 (2) The study expected to produce a relapse (recurrence of symptomatology) in many patient-subjects in order to attain its objective to predict better relapse, particularly of those who would exhibit such severe symptoms as "bizarre behavior, self-neglect, hostility, depressive mood

100. For example, the IRB at Yale-New Haven Medical Center "currently consists of 26 members of whom 15 are full-time medical school faculty. . . The other 11 committee members include [5 persons affiliated with the Medical Center], a psychological counselor who has . . . no [such] affiliation, 4 medical students ... and 1 student from the School of Public Health." ETHICS AND REGULATION OF CLINICAL RESEARCH, supra note 57, at 330.

101. For a more critical assessment of IRBs, see ANNAS, supra note 99, at 331-33. For an opposing assessment, see ETHICS AND REGULATIONS OF CLINICAL RESEARCH, supra note 57, at 341-350.

102. Keith H. Nuechterlein \& Michael Gitlin, Research Protocol for Developmental Processes in Schizophrenic Disorders Project: Protocol; Double Blind Crossover and Withdrawal of Neuroleptics in Remitted, Recent-Onset Schizophrenia, HSPC \#86-07-336 1, 6 [hereinafter Protocol] (on file with author). In a 1988 article the investigators gave a clear account of these research objectives:

The present study is a prospective examination of prodromal signs and symptoms of schizophrenic relapse, using a systematic and carefully controlled research design. One important improvement over the previous studies is that relapse was defined as the elevation of psychiatric symptoms to the severe or extremely severe level. Thus, minor symptom fluctuations that might often be inconsequential were not considered relapses. In contrast to the studies that defined the period of observation by the necessity to increase medication to avoid a possible relapse, we can be certain that any prodromal changes that we isolated actually did precede a clear relapse.

Kenneth L. Subotnik \& Keith N. Nuechterlein, Prodromal Signs and Symptoms in Schizophrenic Relapse, 97 J. ABNORMAL PSYChOLOGY 405, 406 (1988). 
and suicidability." 103 (3) The informed consent form signed by the participants was inadequate in disclosing to the subjects the risks which their participation entailed. (4) The IRB approved the research protocol and informed consent form without asking the investigators for clarifications that might have led the IRB to better protect the subjects of research. (5) The subsequent response to the review of the study by the National Institutes of Health's Office for the Protection of Research Risks (OPRR) did not go far in remedying the problems which came to OPRR's attention.

I also want to emphasize at the outset that my analysis is limited to a review of one of the research protocols, including the informed consent form approved by UCLA's IRB, the action taken by the OPRR, once parents of one of the subjects had lodged a complaint about the study and a perusal of the psychiatric literature pertinent to the research project. ${ }^{104}$ I cannot address what might have been disclosed to the subjects in conversations between them and the investigators; about that I have no knowledge. I can only note that the data available from the protocol and the OPRR review hardly suggests that scrupulous attention was paid at any point to full disclosure and consent.

The UCLA experiment was designed to make an important contribution to a better understanding of the need for continuous medication following patients' recovery from a recent onset of schizophrenic disorder. Thus, the research project sought to identify patients who can function without medication because antipsychotic medication can cause tardive dyskinesia, a syndrome consisting of involuntary and potentially irreversible movements for which no known treatment exists. ${ }^{105}$

All potential patient-subjects were being followed in UCLA's After Care Clinic. ${ }^{106}$ The study, according to the protocol, consisted of two sequential phases. ${ }^{107}$ In the first phase, lasting for twenty-four weeks, the patientsubjects were randomized, in a double-blind design, ${ }^{108}$ to one of two groups. The first group received a standardized dose of $12.5 \mathrm{mgm}$ of prolyxin decanoate, an antipsychotic medication, every two weeks, while the second was injected with a placebo, an inert, therapeutically ineffective substance. After twelve weeks, the injections given to members of each group were reversed so that those who had been receiving medication now received a

103. Id.

104. These and all other discussed unpublished documents are in the possession of the author and available upon request.

105. In some patients symptoms of tardive dyskinesia disappear within several months after antipsychotic drugs are withdrawn, but withdrawal of antipsychotic medication does not guarantee that symptoms will vanish. In some patients, symptoms may persist indefinitely. DORLAND's ILLUSTRATED MEDICAL DICTIONARY 517-18 (27th ed. 1988).

106. See infra note 134 and accompanying text.

107. Protocol, supra note 102.

108. See supra note 30. 
placebo, and vice versa. In the second phase, "all clinically appropriate patients" received no medication, i.e., those who were still on prolyxin were also deprived of the active drug. ${ }^{109}$

The patient-subjects were then followed for at least one year unless "1) the subject withdraws permission for the study or 2) clinical relapse or psychotic exacerbation occurs." 110 Criteria for psychotic relapse included "[high scores on test measures] for Hallucinations, Unusual Thought Content, or Conceptual Disorganization; [for] psychotic exacerbation [fairly severe recurrence of symptomatology; and] for relapse-other type, [high scores] on scales of bizarre behavior, self-neglect, hostility, depressive mood, and suicidability." ${ }^{\prime \prime \prime}$ Apparently the patient-subject's therapist was authorized in the first double-blind phase of the study to break the code for "clinical reasons" but the protocol contained no information, and therefore the IRB could not know, as to when the therapist might take such action. Clearly the intent was to tolerate severe recurrences in symptomatology. Once that had happened "the patient [would] be withdrawn from the study."

The investigators noted in the protocol's section on "Potential Benefits" that since "no study shows $100 \%$ relapse in schizophrenics withdrawn from antipsychotics, unquestioned maintenance treatment may for any particular patient involve much risk and little benefit. At present, there is little consistent data regarding predictive factors for patients at low risk of relapse without pharmacotherapy." 113 In that section the investigators also stated

that clinical relapse or psychotic exacerbation can be expected to occur in at least some of our patient subjects. However, since most of our patients have been requesting drug withdrawal for months, and since our knowledge as to which acute schizophrenic patients will relapse following drug withdrawal is very meager, we feel this risk is justified, especially in view of the risk of tardive dyskinesia with long-term antipsychotic use. Withdrawal from antipsychotic medication one year after the psychotic episode is not unusual in standard psychiatric practice for patients with acute, nonchronic schizophrenia, since little clear evidence exists regarding longer-term prophylactic effects for this nonchronic population. ${ }^{114}$

It is true that many schizophrenic patients complain about the side effects of anti-psychotic medication. However, therapists who believe that such treatment is clinically indicated generally do their level best to impress on patients the need for remaining on medication or to encourage its resumption as soon as symptoms recur. In the UCLA study, on the other hand, all patients

109. Protocol, supra note 102, at 4.

110. Id. at 6.

111. Id. (emphasis supplied).

112. Id.

113. Id. at 7.

114. Protocol, supra note 102, at 8. 
were withdrawn from medication, indeed required to do so, for research purposes until the needs of the study, and not those of the individual patient, had been satisfied. ${ }^{115}$ The expectation of relapse was an integral aspect of the research design; it was not an unfortunate consequence of treatment but one which the investigators deliberately induced. This is particularly problematic because of the continuing controversy in psychiatric circles as to whether relapse leads to additional, at times irreversible, injury. ${ }^{116}$

The consent form submitted to the IRB for review and approval informed prospective patient-subjects that "the purpose of this study is to take people like me off medication in a way that will give the most information about the medication, its effects on me, on others and on the way the brain works."117 It mentioned that an inactive substance (placebo) or an (active) medication would be randomly administered during the first phase and that then "all medication will be stopped and that I will continue to receive regular care at the UCLA After Care Clinic."118 Stating it in that way could only confuse potential subjects. In the same sentence they were told that medication would be stopped and that they would continue to receive regular care, without alerting them in most explicit language that "regular care" was compromised by the withdrawal of medication. ${ }^{119}$

115. The protocol does not make clear whether all the patient-subjects had been on medication for at least one year when enrolled in the study, which, according to the investigators, is the time when "in standard psychiatric practice" patients are often taken off medication. Id.

116. Although the issue is far from settled, many psychiatrists believe that relapse can be permanently harmful to patients: "[S]ome patients are left with a damaging residual if a psychosis is allowed to proceed unmitigated." Richard J. Wyatt, Neuroleptics and the Natural Course of Schizophrenia, 17 SCHIZOPHRENIA BULLETIN 325, 347 (1991). "[N]euroleptic drugs ... if they fully control all acute episodes, may protect against the otherwise inevitable decline of mental function." R. Miller, Schizophrenia as a Progressive Disorder: Relations to EEG, CT, Neuropathological and Other Evidence, 33 PROGRESS Neurobiology 17, 35 (1989).

117. Keith Nuechterlein, Informed Consent Agreement for Patients (Version 1): Double-Blind Drug Crossover and Withdrawal Project 1 (July 1988) [hereinafter Consent Agreement 1] (on file with author).

118. Id.

119. Being absolutely clear on this point was important since the subjects were recruited from the Continuing Care Program of The Neuropsychiatric Institute UCLA. The brochure, given to patients enrolled in this program, contained the following information:

THE CONTINUING CARE PROGRAM . . .

. . . is a specialty service combining treatment, research, and training in the care of the individual with psychotic symptoms. Jointly sponsored by NIMH, UCLA, Camarillo-NIP, and the Clinical Research Center, the Program offers continuing care to people who are experiencing their first psychotic episode.

The Program includes inpatient and outpatient treatment as well as an active follow-up evaluation of each person. Fully integrated with these services is a research project aimed at increasing understanding and knowledge of the factors that are related to relapse and remission.

PURPOSE 
Moreover, the patient-subjects were not informed at the beginning of the study that already during the first phase they would not necessarily receive optimal individual treatment, but only a standardized dose of $12.5 \mathrm{mg}$ of prolyxin. Such a standardized dose can itself lead either to a return of symptomatology or produce unnecessary side effects because it is known that the amount of prolyxin must be tailored to the individual needs of patients with some requiring larger or smaller amounts of medication. ${ }^{120}$ The consent form then goes on to describe in considerable detail the psychological tests that would be administered to the patient-subject during the study period. That aspect of the research could have been presented in a more abbreviated fashion and surely, in light of other omissions, did not deserve the space it was given.

The goal of the Program is to assist persons in making a successful adaptation to life in the community and to improve their daily living and social skills. An equally important goal is to facilitate the family's coping skills for dealing with mental illness. Where appropriate, consultation with other community agencies and social support networks is provided.

...

AFTERCARE CLINIC

A range of outpatient services are offered through the Aftercare Clinic at the UCLA Neuropsychiatric Institute. Following discharge, patients and their families are provided:

Group Therapy: in small groups, patients learn problem-solving skills and interpersonal effectiveness.

Family Education: counseling is aimed to upgrade the entire family's coping skills and understanding of the illness, and to facilitate use of resources both within the family and the community.

Medication is administered at the lowest optimal dose to maximize coping with symptoms and stressors and to minimize side effects.

\section{PARTICIPATION}

... is voluntary by patients and families in both the research and the clinical services.

It is expected that a voluntary agreement to participate for a minimum of two years be made at the point a patient joins the Program.

UCLA Neuropsychiatric Institute, Continuing Care Program of the Mental Health Clinical Center 1-3 (on file with author). Since the Aftercare program serves dual objectives, treatment and research, any experimental interventions needed to be specified and differentiated from therapy with the greatest of care, particularly whenever the research component compromised therapeutic intentions.

120. See PHYSICIANS' DESK REFERENCE 619 (47th ed. 1993) (“Appropriate dosage of Prolyxin Decanoate (Fluphenazine Decanoate Injection) should be individualized for each patient. . . . The optimal amount of the drug and the frequency of administration must be determined for each patient, since dosage requirements have been found to vary with clinical circumstances as well as with individual response to the drug."); TEXTBOOK OF NEUROPSYCHIATRY 682 (Stuart C. Yudosky \& Robert E. Hales eds., 2d ed. 1991) ("Blood levels vary widely in different patients given the same dose of a neuroleptic. ... [T]here is no established correlation between serum concentration and clinical response."); Robert F. Asarnow \& Stephen R. Marder, Differential Effect of Low and Conventional Doses of Fluphenazine on Schizophrenic Outpatients with Good or Poor Information-Processing Abilities, 45 ARCHIVE GEN. PSYCHIATRY 822 (1988). 
With respect to significant risks and benefits the following information was provided:

I understand that during blood drawing, I may experience pain from the needle prick, a small amount of bleeding, infection or black and blue marks at the site of the needle mark which will disappear in about 10 days.

I understand that because of the withdrawal of active medication, I may become worse during this study and that either a relapse of my initial symptoms or new symptoms may occur. I understand that I will not be charged for the active medication or the placebo that I am provided during this study. If I do show a significant return of symptoms, I understand the clinic staff will use active medication again to improve my condition. If I would require hospitalization during this study, although this is not likely, I understand that the clinic staff would help to arrange an appropriate hospitalization but the research project would not pay for the hospitalization.

I understand that I may benefit from this study by being taken off medication in a careful way while under close medical supervision. The potential benefits to science in this study are that it will increase my doctor's knowledge of the relationship between the medication, its effect on people such as myself, and on the way the brain functions in certain forms of mental illness.

I understand that my condition may improve, worsen or remain unchanged from participation in this study. ${ }^{121}$

No information was provided as to what constituted a "significant return of symptoms," that it could mean a return of hallucinations, conceptual disorganization, self-neglect, depressive mood, or suicidal ideation. Potential patient-subjects under the care of mental health professionals in an Aftercare Clinic might very well have believed that "significant" did not encompass such dire consequences. Moreover, while it was acknowledged that "I may become worse," the consent form of July 1988 did not state that at that time it was known that of those patient-subjects enrolled in the study so far, eighty-eight percent had suffered a relapse. ${ }^{122}$

In light of the high relapse rate it was misleading to aver "that my condition may improve, worsen or remain unchanged." The odds favoring

121. Consent Agreement 1, supra note 117, at 2.

122. Of the 24 patients who entered the drug withdrawal period, 21 have ultimately had psychotic exacerbations or relapses, ranging from 17 to 123 weeks after the last fluphenazine administration. For these 21 exacerbation/relapses plus the 3 psychotic exacerbations during the placebo phase of the crossover, the mean time to exacerbation/relapse is 33 weeks. Of these 24 patients who have developed an exacerbation/relapse after medication discontinuation, 5 exacerbation/relapses occurred after 60 or more weeks $(21 \%), 6$ after $40-59$ weeks $(25 \%), 7$ after 20-39 weeks (29\%), 4 after 10-19 weeks (17\%), and 2 after less than 10 weeks $(8 \%)$. Three more remain well after 104, 30 and 23 weeks. Keith H. Nuechterlein, Grant Application: Developmental Processes in Schizophrenic Disorders, RD 1 MH 37705-07, 1, 84 (Nov. 15, 1988) (on file with author). 
relapse were far too great; few subjects would "improve" or "remain the same." Finally, it is not only ironic but also misleading that the risks of a needle prick were discussed in such exquisite detail. Such a forthcoming and honest acknowledgement could only leave patient-subjects with the impression that the investigators would disclose any other risks in similar detail and with similar candor.

The informed consent form should have highlighted in bold face that the primary objective of the study was to advance knowledge for the sake of future patients and, depending on outcome, only of value to some of the subjects' future well-being. The form, further, should have acknowledged that the study was not designed to attend to their individual therapeutic needs, and that the subjects exposed themselves to considerable risks. Moreover, the patientsubjects were not presented with any information about the merits of not joining the research project. They were deprived of considering that alternative. To be sure, the informed consent form must be supplemented by the oral informed consent process ${ }^{123}$ and the latter may be more important than the former in providing patient-subjects with meaningful disclosures, particularly since the forms are generally written in such incomprehensible language. When, however, as in this instance, the written document provided incomplete information, and with insufficient candor, patient-subjects who are intent on reading it are deprived of crucial information. From a different perspective, the consent form, as written, cannot help but create concerns, though most difficult to substantiate, as to whether the oral informed consent was similarly flawed. ${ }^{124}$

123. UCLA claims to have presented much of the information required for informed consent to patient-subject's orally. Department of Health and Human Services (DHHS) regulations at 45 C.F.R. § 46.117 require, however, that the elements of legally effective Informed Consent (specified at 45 C.F.R. $\$ 46.116(1992)$ ) be embodied in the written Informed Consent Document.

124. The special care that, I believe, must be given to the informed consent process whenever the research-therapy distinction, see supra text accompanying footnotes 19-34, is in danger of being compromised, is illustrated by a comment made by my respected colleague and friend Robert J. Levine who read an earlier draft of this paper:

My perception of the investigators' motivation continues to be very different from yours. I see this as an instance of opportunistic research. The physician-investigators did not expose subjects to the risks of withdrawal from medication in order to do research. Rather, in the light of their reading of the results of observations published by others, they decided that it would be in the medical interests of these patients to have their medications withdrawn. Although they knew that some of them would develop symptoms, they could not predict which. What they planned to do was to keep a careful record of their observations of those who developed symptoms. They further made plans to remove patients from the study and treat them if certain specific criteria were met.

Letter from Robert J. Levine to Jay Katz (Sept. 24, 1993) (quoted by permission). Viewing the "motivation" of the investigators as "opportunistic research" in the service of the "medical interests of these patients" co-joins therapy and research. In the UCLA study the patient-subjects' medical interests were subordinated to the inflexibility of the research design. See supra text 
After complaints about the study had come to OPRR's attention ${ }^{125}$ and it had discussed the problem with UCLA, a letter from OPRR detailed "the agreed-upon actions" which UCLA would now take:

[P]rovide (a) more detailed information regarding the risks associated with lengthy withdrawal of antipsychotic medication, including information regarding the likely rates of exacerbation or relapse and the consequences thereof; (b) an indication that, in the event of such exacerbation or relapse, it is likely that antipsychotic medication will need to be resumed; (c) a description of the risks associated with continued fixed dose medication treatment; and (d) a disclosure of alternative courses of treatment . . . ${ }^{126}$

....

The Continuing Care Brochure will be modified to ensure that it accurately reflects the parameters of the After Care Program's research protocols. ${ }^{127}$

In addition, OPRR required the following additional actions:

(1) No new subjects should be enrolled in this research until the revised Informed Consent Documents have been reviewed and approved by the UCLA

accompanying notes 56-59. It is this fact that needed to be highlighted in the consent form, notwithstanding any accompanying therapeutic motivations of the investigators. Viewing research also as treatment, see supra text accompanying footnotes $28-34$, invites confusion in the minds of all participants as to who they are: physicians or investigators, patients or subjects. In turn, it makes it easier for investigators to take license because of their "benevolent therapeutic intentions." Furthermore, the "specific criteria [for removal from the study]" noted by Levine included relapse to the severest level of psychosis, an unacceptable criterion for clinical practice. Long before that point is reached psychiatrists would urge their patients to resume taking medication. Thus, I would argue that the physician-investigators' conduct was motivated by their research interest, even though they might eventually also bestow benefits on their subjects or future patients. If I am correct, then the patient-subjects' medical interests are in this instance different from, and should not be conflated with, the investigators' research interests.

125. The complaint was lodged by Bob and Gloria Aller, parents of one of the subjects. The story of Greg's participation in, and gradual deterioration during, the study is graphically described in a recent article: Eventually, he not only dropped out of college, but also

took out a carving knife, walked to the door of his mother's kitchen, [and thinking that] "my mom was possessed by the devil," . . ."[m]y plan was to scare the devil out of her literally." The Allers began barricading their bedroom door at night. [A few days later] he moved out, [and when he saw Nuechterlein's partner, Dr. Michael Gitlin, Greg kept this information from him, and thus Gitlin] noted "Moved out from parents. Says no symptoms present. Finishing the semester."

James Willwerth, Tinkering with Madness, 42 TIME 41-42 (Aug. 30, 1992). It took five more months, and the article describes what happened during that interval, before he was remedicated at UCLA. Id.

126. Letter from J. Thomas Puglisi, Acting Chief, Compliance Oversight Branch of the Office for Protection from Research Risks (OPRR) to Richard Sisson, Senior Vice Chancellor of Academic Affairs at the University of California Los Angeles 1 (Aug. 19, 1992) (on file with author).

127. Id. at 2. 
Institutional Review Board (IRB).

(2) The revised IRB-approved Informed Consent Documents should be used to obtain renewed consent from all subjects currently participating in this research, including subjects for whom clinical monitoring constitutes the only research involvement.

(3) Copies of the revised IRB-approved Informed Consent Documents and of the revised Continuing Care Brochure should be forwarded to OPRR as soon as possible.

(4) UCLA should consider, and OPRR strongly recommends, contacting former research subjects in writing to provide them with the additional information included in the revised Informed Consent Documents. Copies of such communications with former subjects should be forwarded to OPRR as soon as they become available. ${ }^{128}$

OPRR did not insist that UCLA stop the research project immediately, or at least, that the patient-subjects be examined by independent psychiatrists in order to assess their individual treatment needs. In light of what already had transpired, such an opportunity would have made it easier for patient-subjects to decide whether they wished to continue in, or withdraw from, the study. Moreover, in light of the serious deficiencies in the informed consent form, ${ }^{129}$ which is one of the prime responsibilities of IRBs to review, ${ }^{130}$ OPRR did not institute a thorough investigation of the practices of UCLA's IRB. OPRR's evaluation was sufficiently critical of the IRB process to suggest that the IRB's review of other research proposals may be similarly flawed. ${ }^{131}$ Undertaking such an investigation was even more pressing in this case since several subject-patients suffered severe schizophrenic relapses, ${ }^{132}$ and one young man allegedly committed suicide. ${ }^{133}$

128. Id.

129. Even after modifying the consent forms initially used, UCLA continues to deny any wrongdoing and contends that the forms and process used to obtain initial consent were appropriate. See Letter from Richard Sisson, Senior Vice Chancellor of Academic Affairs at the University of California Los Angeles to J. Thomas Puglisi, Acting Chief, Compliance Oversight Branch of the OPRR 4-5 (Sept. 17, 1992) (on file with author).

130. Federal Regulations instruct IRBs to "determine that all of the following requirements are satisfied: . . . (4) Informed consent will be sought from each prospective subject ... in accordance with, and to the extent required by $\S 46.117$." 45 C.F.R. $\$ 46.111$ (4) (1992).

131. The copy of the letter from OPRR to UCLA, made available to me through the Freedom of Information Act, excluded three paragraphs. They may have contained additional criticisms of UCLA's conduct in this case. See supra note 126.

132. Subotnik \& Nuechterlein, supra note 102.

133. One participant in the UCLA project committed suicide on March 28, 1992, after being taken off psychotropic medication. Sandy Rovner, Ethics Concerns Raised in Schizophrenia Study, Wash. POST, Sept. 29, 1992, at H7. The Federal Regulations require that "[w]here appropriate, the research plan makes adequate provision for monitoring the data collected to insure the safety of subjects." 45 C.F.R. $\$ 46.111(6)$ (1992). The protocol, however, did not describe in sufficient detail the special monitoring that would be provided, even though some of 
The revised informed consent form, while an improvement over the previous one, continues to leave patient-subjects uninformed, inter alia, about the specific severity of relapse which they might suffer, mentioning only "difficulties in relationship with others and problems with work or school"; or what specific "psychotic symptoms or severe symptoms" will lead to providing medication once again. It does not present in any meaningful detail the advantages and disadvantages of participating in the study or receiving customary treatment for their condition. The consent form did not state with sufficient clarity that the primary objective of the study was to conduct research for the sake of future patients, perhaps of benefit to those enrolled in this study in the future, and that it was not therapy for the subject's individual present needs. While the consent form now admits that " $70-80 \%$ of patients who have entered this study in the past have experienced a psychotic exacerbation or relapse within one year" and that "I may become worse during the study," it says nothing about what subjects specifically should consider, and reflect on, before exposing themselves to these risks. On the other hand, with respect to benefits it is noted that withdrawal of medication will keep them from "developing tardive dyskinesia which involves abnormal movements of the face, hands, legs or trunk." And the form goes on to emphasize, "I may benefit from this study by being taken off medication in a careful way while under close medical supervision." 134 The risks deserved at least similar detailed explication and prominence.

What transpired in this study is not unique to UCLA; it is symptomatic of the flawed nature of current regulations and current practices protecting the human rights of research subjects. These flaws, as I have argued throughout this article, extend from the Federal Regulations themselves ${ }^{135}$ to the supervision of projects by IRBs and OPRR. Thus, my analysis of UCLA's consent form should not be taken merely as a critique of the nature and depth

the research subjects could suffer a severe relapse. The protocol only stated that "a member of the clinic staff will meet regularly as needed" with the patient. See supra note 102.

134. Keith Nuechterlein, Informed Consent Agreement for Patients: Double-Blind Drug Crossover and Withdrawal Project 3 (Sept. 1992) (on file with author).

135. Shamoo and Irving recently noted that recommendations by various Federal Commissions to consider persons with mental illness as members of a vulnerable group who deserve special protection whenever they participate in research were not implemented. They learned that "[this] outcome was the result in large part of opposition from researchers on mental disorders who claimed that the population in question were no more vulnerable than most persons with severe medical disorders and that the suggested limitations would seriously restrict research on mental disorders." Shamoo and Irving concluded that "the issue of using persons with mental illness as human research subjects has been lost in the shuffle, due in part to the lobbying effort of some researchers on mental disorders." They also raise the important question, "what was the justification for delegating to local IRBs the essential responsibilities for affording protections for persons with mental illness ... ?" Adil E. Shamoo \& Dianne N. Irving, Accountability in Research Using Persons With Mental Illness 1, 2 (1994) (forthcoming article, on file with author). 
of the information that was or was not included in the written document, but, more importantly, as a critique of the entire informed consent process. The problems with this study, as with many others, are: (1) subject-patients' consent was manipulated; (2) trivial and non-trivial risks were insufficiently distinguished; (3) the severity of predictable risks was not highlighted nor was the incidence of their likelihood disclosed; and (4) the risks and benefits of non-participation were neither sufficiently disclosed nor satisfactorily discussed. Under these circumstances, patient-subjects were not offered a meaningful choice whether or not to participate in the study. ${ }^{136}$

\section{CONCLUSION}

The history of experimentation with human beings testifies to physicianscientists' real and caring dedication to the alleviation of mankind's pain and suffering from the ravages of disease. It also testifies to the carelessness with which human beings have been recruited for participation in research, a carelessness that has been too readily obscured by the caring dimension of scientists' work. My colleague, the late Robert Cover, when writing about judicial sentencing reminded us that "judges deal pain and death."137 $\mathrm{He}$ went on to say that "persons [he meant judges but he could have said the same about physician-scientists as well] act within social organizations that exercise authority violently without experiencing . . . the normal degree or inhibition which regulates the behavior of those who act autonomously."138.

If informed consent is to fulfill its promise of protecting the rights of research subjects to autonomy and self-determination, we must ponder Hans Jonas' challenge:

Let us not forget that progress is an optional goal, not an uncompromising commitment. [A] slower progress in the conquest of disease would not threaten society, grievous as it is to those who have to deplore that their particular disease be not yet conquered, but that society would indeed be threatened by the erosion of those moral values whose loss possibly caused by too ruthless a pursuit of scientific progress, would make its most dazzling triumphs not worth having. ${ }^{139}$

Jonas is concerned about the erosion of medicine's and society's moral integrity resulting from violations of the dignity of research subjects.

Some advances in medicine might have been slower in coming had physician-investigators pursued their clinical research less aggressively by not engineering consent. Would delay have been a price worth paying, even

136. See supra notes $32-34$ and accompanying text.

137. Robert Cover, Violence and the Word, 95 YALE L.J. 1609 (1986).

138. Id. at 1615 .

139. Hans Jonas, Philosophical Reflections on Experimenting with Human Subjects, 98 DaEdalus 219, 245 (1969). 
though the suffering of future patients might have remained for a while longer without relief? Or is medical progress not an optional goal but one to which individual autonomy and self-determination must yield? Answers to these questions ultimately depend on one's vision of the future and the price our generation is willing to pay for the sake of medical progress at the expense of respect for the persons who are asked to make progress possible.

While in this article my personal views on these questions clearly emerge, my purpose in writing it has been less to advocate their implementation and more to draw attention to the fact that in the pursuit of scientific progress we have largely paid lip service to the subjects' rights to be fully informed. In setting forth the nature and quality of the conversations between physicianinvestigators and their patient-subjects, I wanted to highlight the wide chasm that separates contemporary rhetoric from practices in implementing human subjects' rights to make their own decisions about serving as means for others' ends.

In juxtaposing in the title of this article human rights and human experimentation, I appreciate that the contours of such rights are still illdefined. The idea that human beings possess rights to inviolate dignity is of recent origin and in need of more precise construction and surely in need of a deeper commitment. However, it is an idea that since World War II has begun to capture the imagination of the world community, as attested by the many United Nations' resolutions on human rights. ${ }^{140}$

It is also an idea, in language of constitutional rights, that has captured the imagination of some of the Justices of the United States Supreme Court. In 1987, the Court was faced with the question of whether the constitutional rights of James Stanley, an army serviceman, were violated when in 1958, without his knowledge, LSD was administered to him in an army experiment to study the effects of this drug on human beings. ${ }^{141}$ Stanley had sued the government under the Federal Tort Claims Act. The Court split five to four, and Justice Scalia, writing for the majority, concluded in a highly technical opinion that to allow Stanley to sue the army successfully would be a judicial intrusion upon military matters that "would call into question military discipline and decision making." 142 Justices O'Connor and Brennan wrote separate dissenting opinions, joined by Justice Marshall and, in part, by Justice Stevens. Justice Brennan began by arguing that the Court was wrong in holding

that the Constitution provides him with no remedy, solely because his injuries were inflicted while he performed his duties in the Nation's Armed Forces.

140. See supra note 44 and accompanying text.

141. United States v. Stanley, 483 U.S. 669 (1987). For a more extended discussion of Stanley, see George J. Annas, The Nuremberg Code in U.S. Courts: Ethics versus Expediency, in THE NAZI DOCTORS AND THE NUREMBERG CODE, supra note 2, at 212-15.

142. Stanley, 483 U.S. at 682. 
If our Constitution required this result, the Court's decision, though legally necessary, would expose a tragic flaw in that document. But in reality, the Court disregards the commands of our Constitution, and bows instead to the purported requirements of a different master, military discipline, declining to provide Stanley with a remedy because it finds "special factors counselling hesitation."143

He concluded his opinion with these words:

The subject of experimentation who has not volunteered is treated as an object, a sample. James Stanley will receive no compensation for this indignity. A test providing absolute immunity for intentional constitutional torts only when such immunity was essential to maintenance of military discipline would "take into account the special importance of defending our Nation without completely abandoning the freedoms that make it worth defending." But absent a showing that military discipline is concretely (not abstractly) implicated by Stanley's action, its talismanic invocation does not counsel hesitation in the face of an intentional constitutional tort, such as the Government's experimentation on an unknowing human subject. Soldiers ought not be asked to defend a Constitution indifferent to their essential human dignity. ${ }^{144}$

In a different context, my former colleague Charles L. Black, Jr. has eloquently advanced the proposition that our Constitution guarantees United States citizens universal human rights which can be asserted against the fifty local state governments. He found such guarantees in the Declaration of Independence, the Ninth Amendment, and the Privileges and Immunity Clause of the Fourteenth Amendment. ${ }^{145}$ What particularly caught my eye were the concluding paragraphs of his article:

I want to add a word about the intentions and hopes that have guided the writing of this paper. First of all, it has seemed not to be generally understood that an amply developed human-rights system, good against the States, is absolutely essential to the moral unity and integrity of the whole nation. This is a thing so obvious that one ought not to have to write about it at all. But much exposure to public discourse has brought home to me that it does need to be written about. As many citizens as possible should be brought to realize that without such a corpus of national human rights law good against the States, we ought to stop saying, "One nation indivisible, with liberty and justice for all," and speak instead of, "One nation divisible and divided into fifty zones of political morality, with liberty and justice in such kind and measure as these good things may from time to time be granted by these fifty

143. Id. at 686.

144. Id. at 708 (quoting Goldman v. Weinberger, 475 U.S. 503, 530-532 (1986) (O'Connor, J., dissenting)).

145. Charles L. Black, Jr., "One Nation Indivisible"; Unnamed Human Rights in the States, 65 ST. JOHN'S L. REV. 17, 25 (1991). 
political subdivisions."146

The time may eventually come when violations of human rights, as in Stanley, will be afforded constitutional protection. Perhaps the recent revelations about radiation experiments conducted during the 1940s and 1950s with retarded boys, newborn infants, pregnant women, prisoners and hospitalized patients, more often than not without full disclosure and consent, ${ }^{147}$ will lead to regulations of research which comport better with the human rights of subjects of research. This will only happen, however, if it is recognized that safeguarding such rights requires not only protection from physical harm but also, and equally important, a commitment to using human beings as means for our ends only with their voluntary consent. ${ }^{148}$ Justice O'Connor put it well in Stanley: "I am prepared to say that our Constitution's promise of due process of law guarantees this much."149 The dissenting Justices in Stanley and Charles Black point medicine in the right direction. In writing this article I wanted to add my voice to theirs by arguing that the caring dimension of medicine also requires taking most seriously the idea that research subjects possess human rights that are inviolate.

146. Id. at 55 .

147. See Gary Lee, U.S. Should Pay Victims, O'Leary Says 800 Were Deliberately Exposed to Radiation, Energy Chief Reveals, WASH. Post, Dec. 29, 1993, at A1; Melissa Healy, Payments Urged for Radiation Test Victims, L.A. TIMES, Dec. 29, 1993, at A1; David Armstrong, State Expects Further 1940s-50s Revelations, Boston GloBE, Dec. 29, 1993, at § 3, p.1; Associated Press, Irradiated Deserve Aid, Energy Says, Chicago Tribune, Dec. 28, 1993, at 1.

148. Any new Presidential Commission or Ethics Advisory Board should also have the authority to formulate research policies that seek to resolve the inevitable tensions between the inviolability of subjects of research and the claims of science and society to advance knowledge. Such a Board's proposed policies should then be subjected to a relentless public debate and eventually approved by Congress. See supra notes 90-101 and accompanying text. Equally important, since biomedical research will continue to open up new frontiers in its quest to advance science, will be the Board's responsibility to promulgate guidelines for the conduct of research to which IRBs must adhere. Finally, such a Board should probably not be located within the Department of Health and Human Services. If it is, its relationship to, and independence from, the Department should be clearly specified. My major contention is this: The moral tensions inherent in human research have been debated at length. We do not need a Board that provides only advice but one that will resolve these tensions as best it can and with continuing authority to do so as we come face to face with new moral dilemmas in the conduct of human research.

149. Stanley, 483 U.S. at 710. 